\title{
VIII. APPENDIX CHAPTER IV
}

Abbreviations / Nr. Pages

Tables

Grain size distribution (Nako)

Tab $\quad 5.4$

330

Determination of the liquid limit

Tab $\quad 6.4$

330

Determination of the plasticity limit

Tab $\quad 7.4$

331

Classification number for the plasticity

Tab 8.4

331

Graphics

Grain size distribution - Graphics

GSD $1.4-15.4$

$332-346$

Bulk mineral analysis - Graphics

BMA $1.4-15.4$

$347-354$

Clay mineral analysis - Graphics

CMA $1.4-15.4$

$354-361$

Simultaneous thermal analysis - Graphics

STA $1.4-2.4$

362 
Table 5.4 Grain size distribution of Nako samples. List of TARA company. Handed over to the author during an interview with Sujoy Chaudhury in 2002.

$\begin{array}{lrrrr} & \text { Tua }^{\mathrm{A}} & \text { Clay }^{\mathrm{B}} & \text { Adobe brick } & \text { [\%] } \\ \text { Coarse gravel } & 0.40 & 0.40 & 4.42 \\ \text { Fine gravel } & 0.80 & 4.04 & 4.01 \\ \text { Coarse sand } & 2.41 & 19.75 & 12.05 \\ \text { Fine sand } & 25.39 & 43.81 & 34.52 \\ \text { Suspendid solids } & 43.00 & 17.00 & 26.00 \\ \text { Clay } & 28.00 & 15.00 & 19.00 \\ \text { Shrinkage } & 5.33 & 2.33 & 3.33 \\ \text { Moisture content } & 1.73 & 1.31 & 6.53 \\ \text { Deformation index } & 8.82 & 3.90 & 8.57\end{array}$

Table 6.4 Determination of the liquid limit $\left(\mathrm{W}_{\mathrm{L}}\right)$ according to A. Casagrande.

\section{2 beats}

Bowl weight: 51.998

Sample moistened with bowl: 79.643

Sample dry with bowl: 70.201

Sample dry: $18.203=100 \%$

Sample moistened: 27.645

$18.203 / 27.645=0.6585-1=0.3415 \times 100=34.15+100=134.15 \%$

\section{2 beats}

Bowl weight: 47.071

Sample moistened with bowl: 68.009

Sample dry with bowl: 60.911

Sample dry: $13.84=100 \%$

Sample moistened: 20.938

$13.84 / 20.938=0.661-1=0.339 \times 100=33.9+100=133.9 \%$

\section{4 beats}

Bowl weight: 47.006

Sample moistened with bowl: 62.036

Sample dry with bowl: 57.083

Sample dry: $10.007=100 \%$

Sample moistened: 15.03

$10.007 / 15.03=0.666-1=0.334 \times 100=33.42+100=133.42 \%$

Result: According to DIN 18122 the liquid limit $\left(\mathrm{W}_{\mathrm{L}}\right)$ for the markalak clay sample 8466, read on scale at 25 beats (see Fig. 11.4) lies at a water content of $133.75 \%$ (giving the geotechnical value). 
Table 7.4 Determination of the plasticity limit $\left(\mathrm{W}_{\mathrm{p}}\right)$. Three specimens from sample 8466 (Spituk) were taken for this examination according to DIN 18122-1:1997-07.

\section{Specimen I}

Bowl weight: 54.735

Sample moistened with bowl: 56.612

Sample dry with bowl: 56.225

Sample dry: $1.49=100 \%$

Sample moistened: 1.877

$1.49 / 1.877=0.794-1=0.206 \times 100=20.618+100=120.618 \%$

\section{Specimen II}

Bowl weight: 54.682

Sample moistened with bowl: 57.881

Sample dry with bowl: 57.203

Sample dry: $2.521=100 \%$

Sample moistened: 3.199

$2.521 / 3.199=0.788-1=0.212 \times 100=21.194+100=121.194 \%$

\section{Specimen III}

Bowl weight: 55.807

Sample moistened with bowl: 59.700

Sample dry with bowl: 58.876

Sample dry: $3.069=100 \%$

Sample moistened: 3.893

$3.069 / 3.893=0.788-1=0.212 \times 100=21.166+100=121.166 \%$

Result: According to DIN 18122 the plasticity limit $\left(\mathrm{I}_{\mathrm{P}}\right)$ lies at water content of $121 \%$ on average (giving the geotechnical value for humidity).

Table 8.3 Classification number for the plasticity $\left(\mathrm{I}_{\mathrm{p}}\right)$ of clays according to Voth 1978 (Minke 1995: 42).

$$
\begin{aligned}
& \mathrm{I}_{\mathrm{P}}[\%]=\mathrm{W}_{\mathrm{L}}[\%]-\mathrm{W}_{\mathrm{P}}[\%] \\
& \mathrm{I}_{\mathrm{P}}[\%]=133.75 \%-121 \%=12.75 \%
\end{aligned}
$$




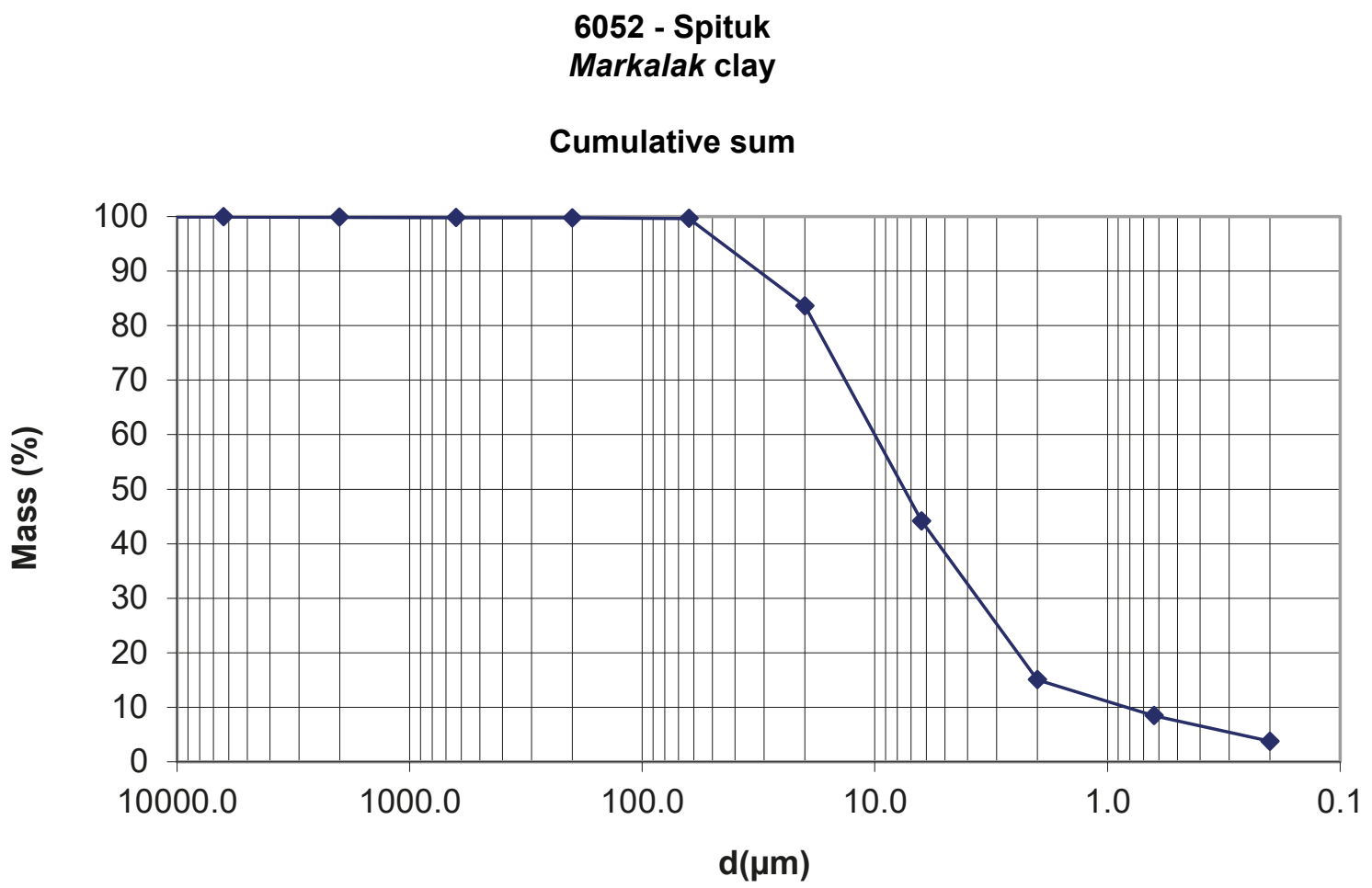

Grain size classes

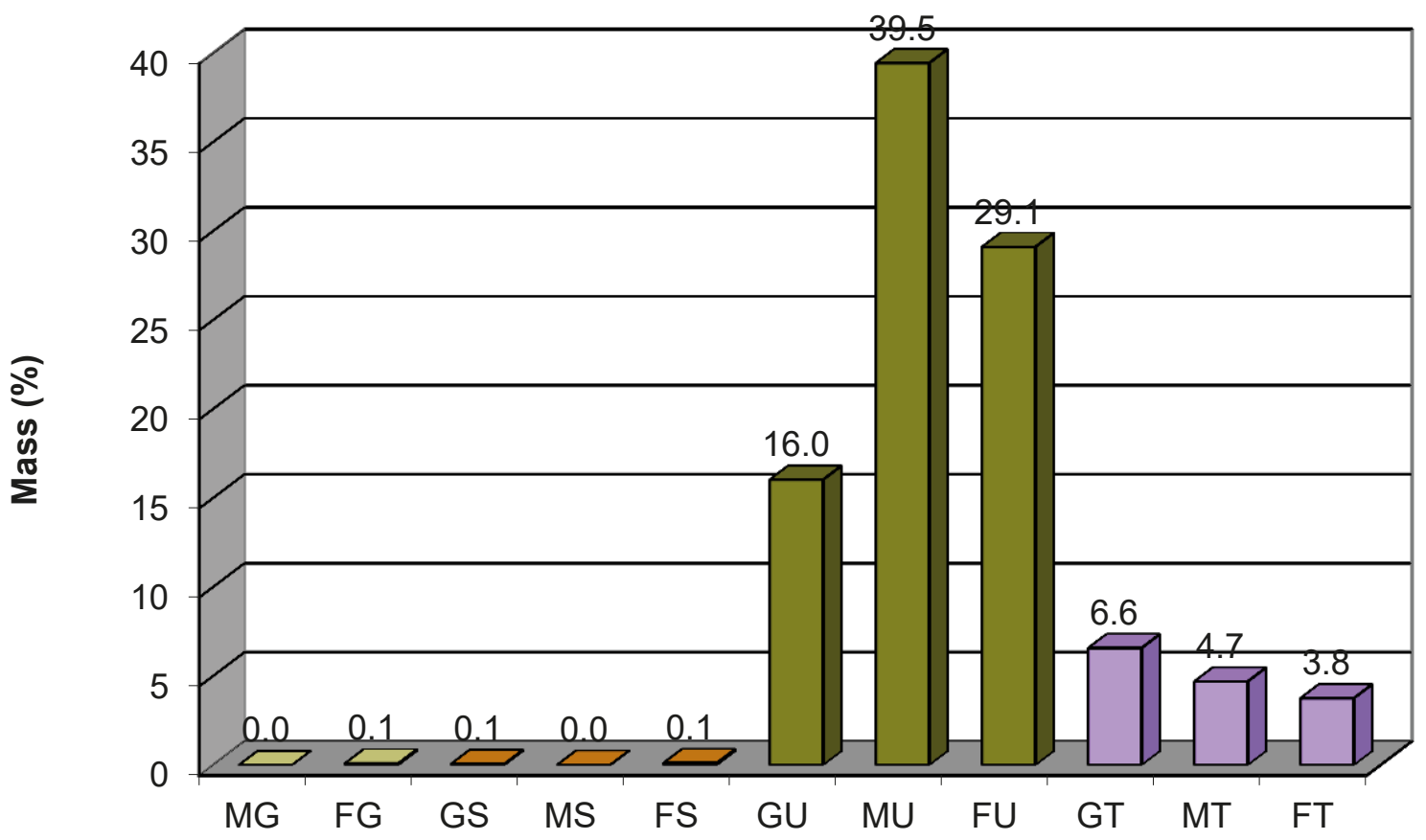

GSD 1.4 Spituk. Sample 6052. Markalak clay. Top: Cumulative sum. Bottom: Grain size classes. 


\section{6 - Basgo \\ Maitreya Lhakhang - plaster on pillar}

Cumulative sum

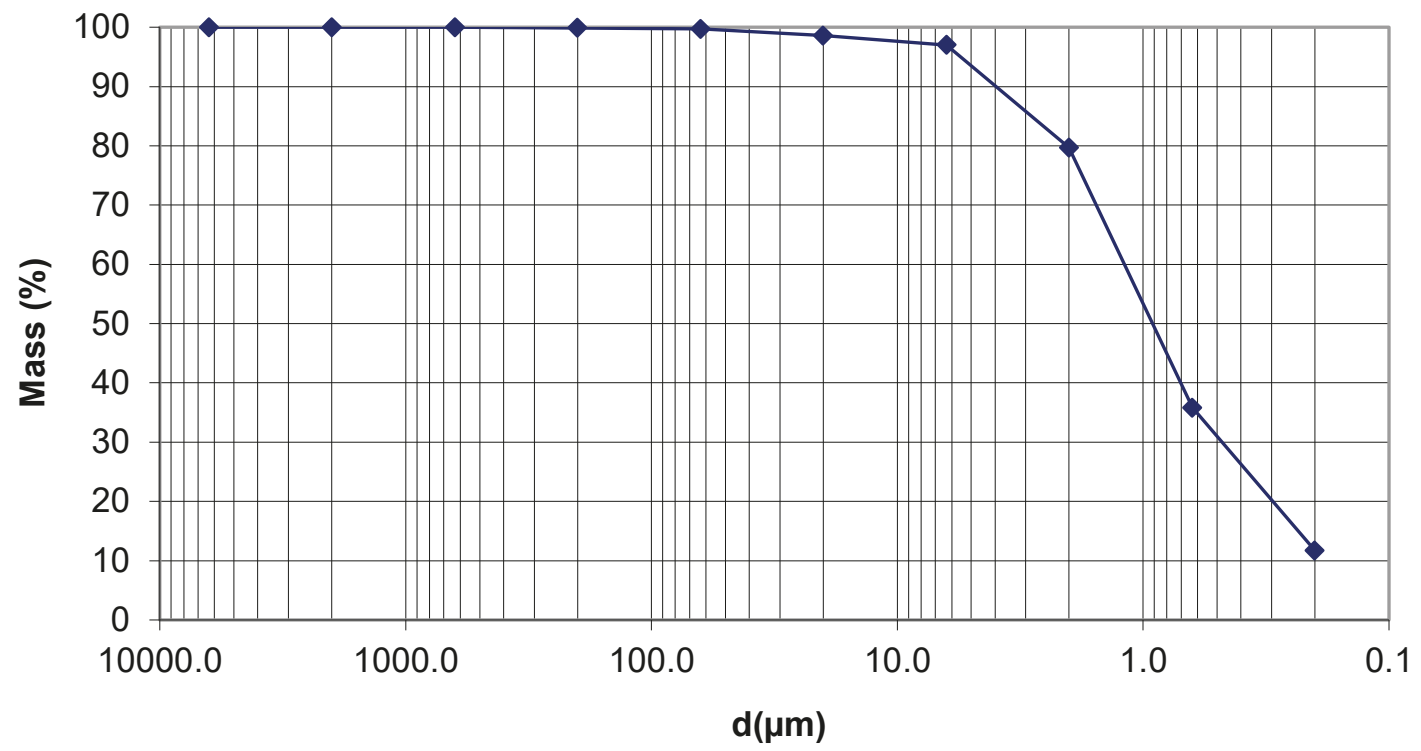

Grain size classes

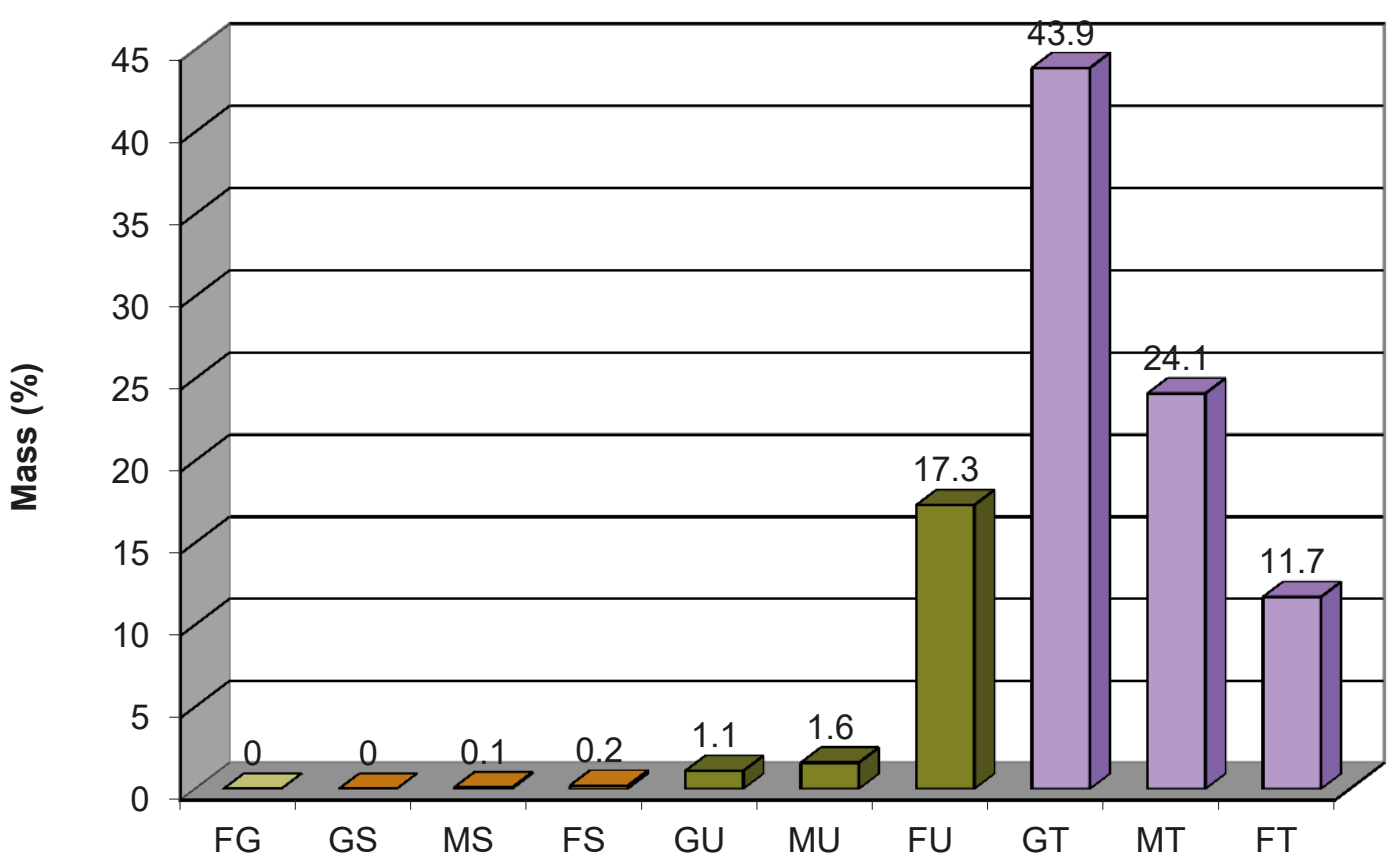

GSD 2.4 Spituk. Sample 8466. Markalak clay. Top: Cumulative sum. Bottom: Grain size classes. 

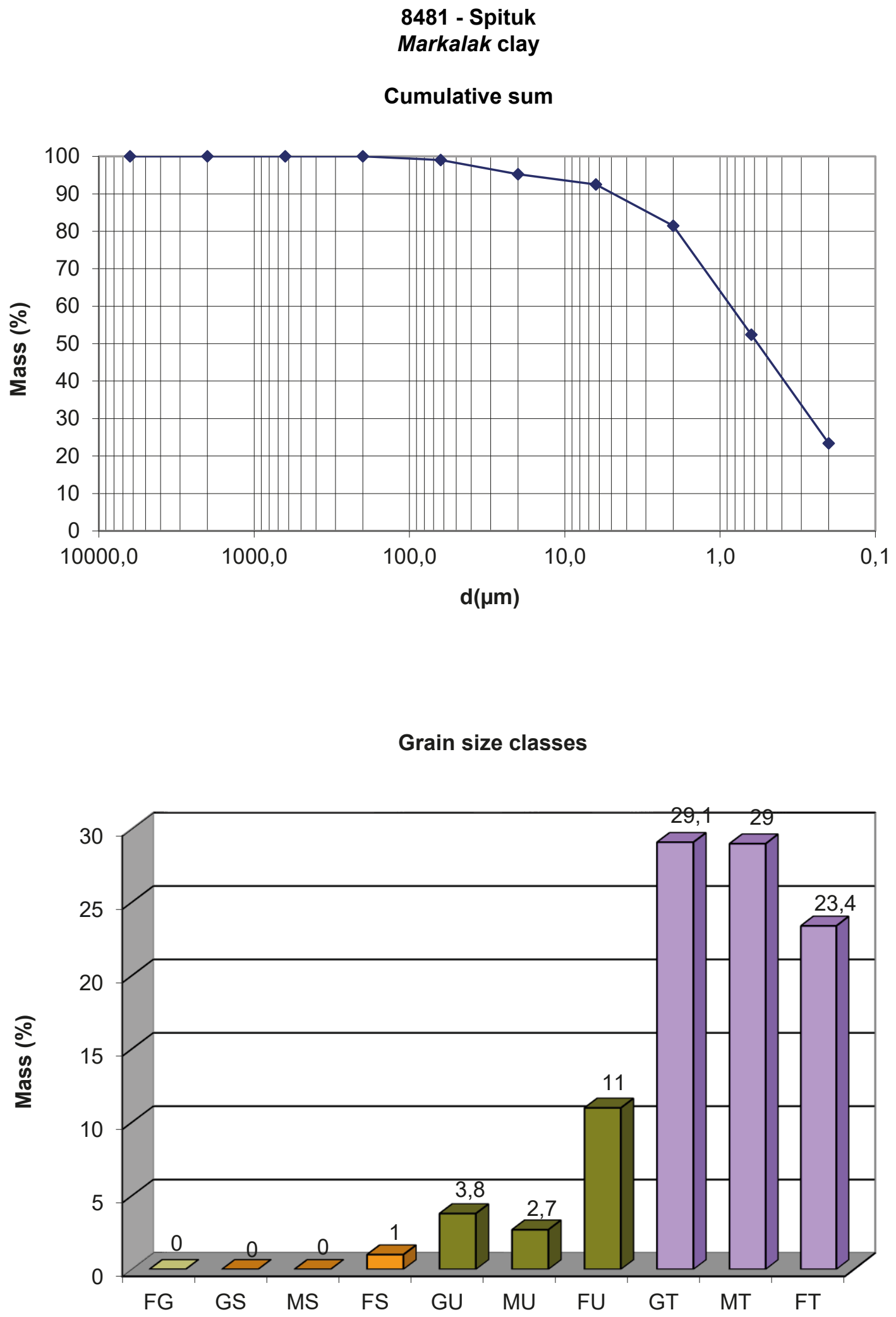

GSD 3.4 Spituk. Sample 8481. Markalak clay. Top: Cumulative sum. Bottom: Grain size classes. 


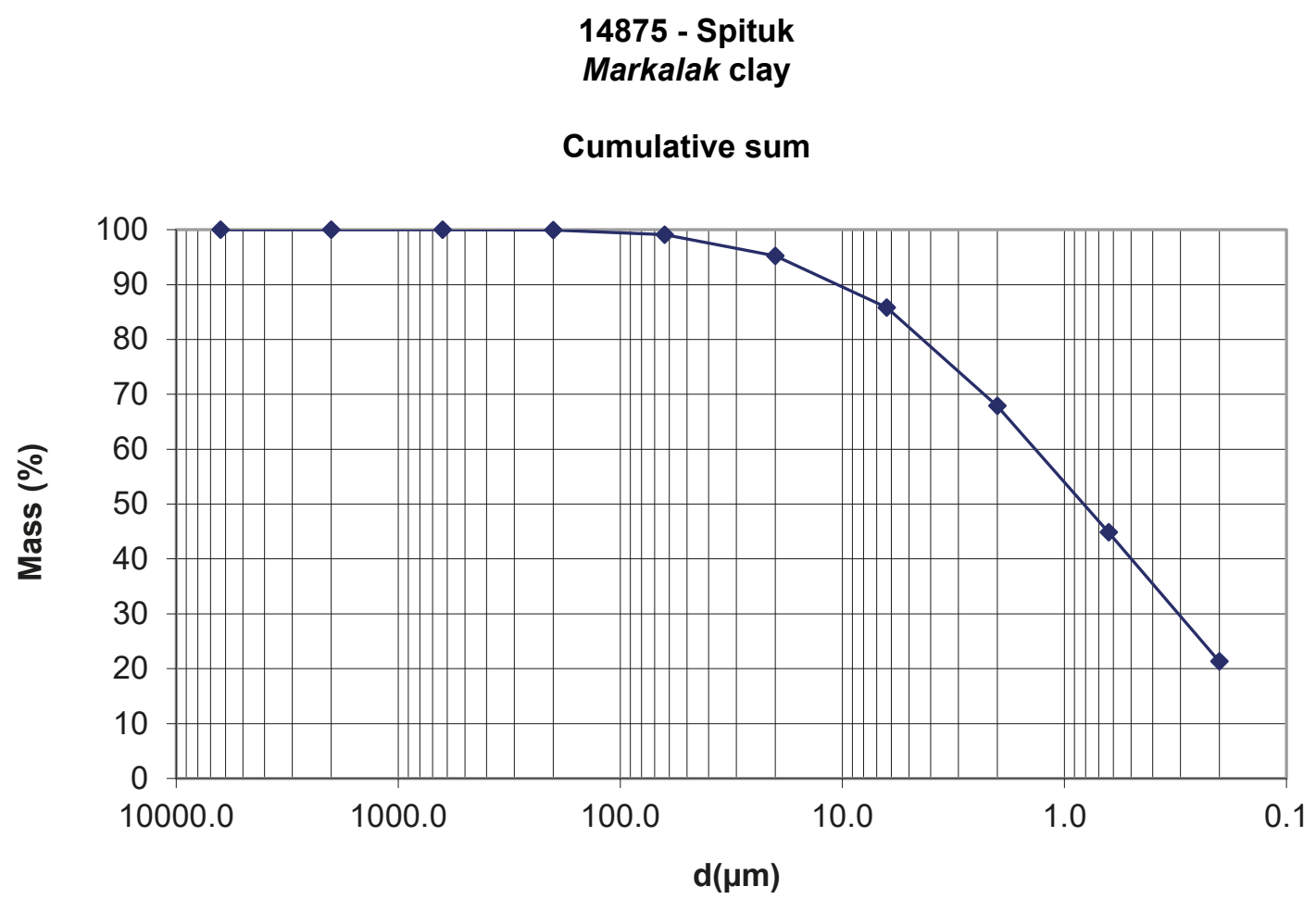

Grain size classes

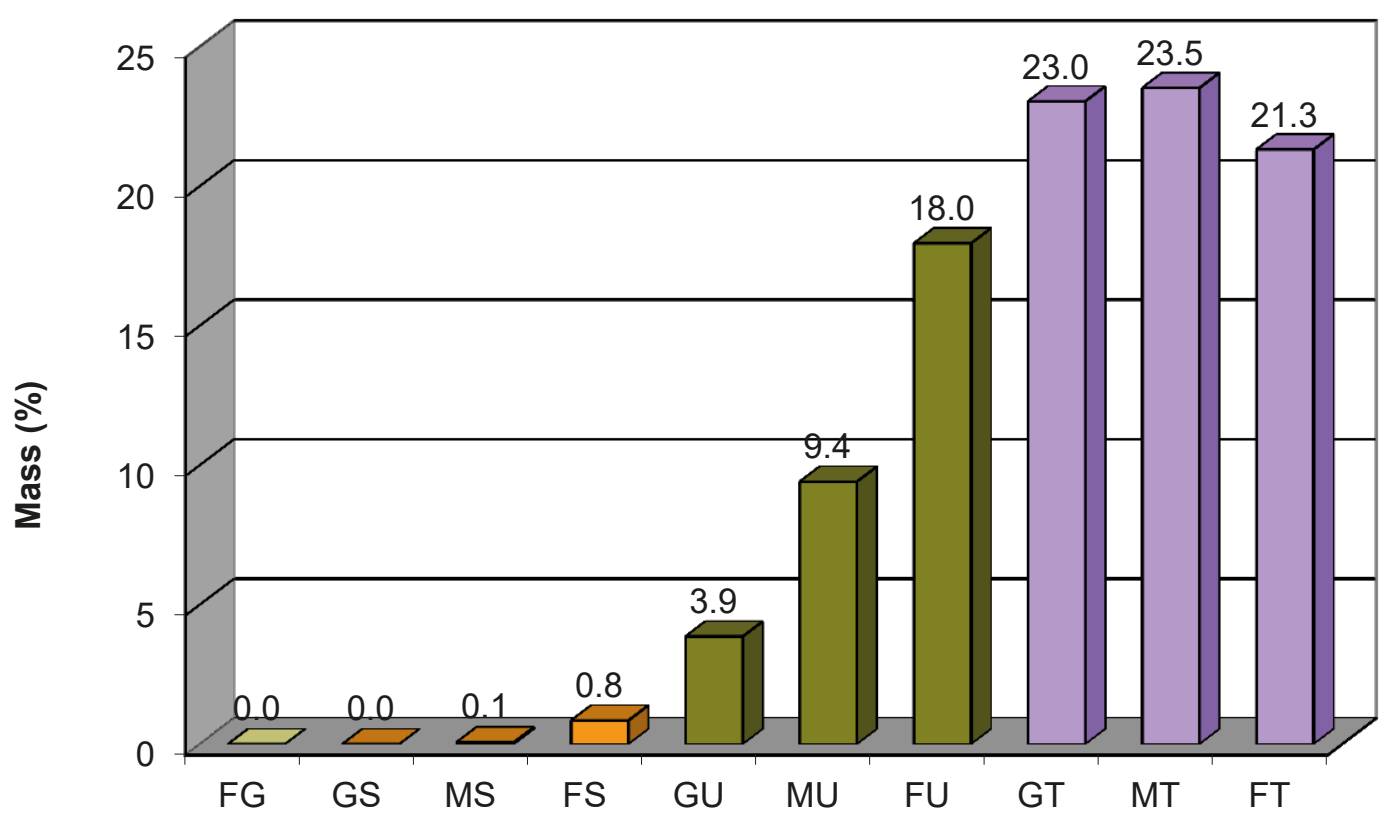

GSD 4.4 Spituk. Sample 14875. Markalak clay. Top: Cumulative sum. Bottom: Grain size classes. 

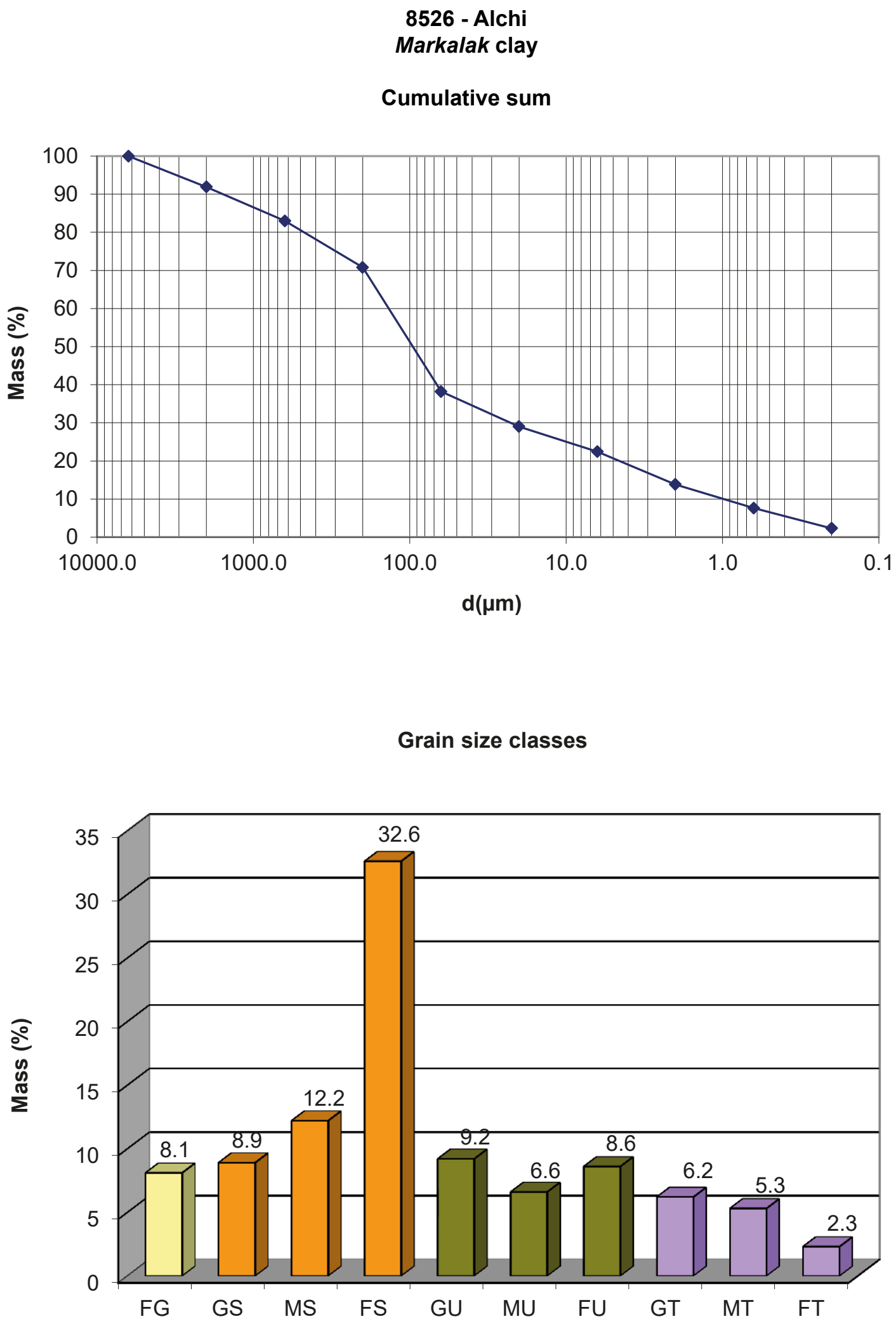

GSD 5.4 Alchi. Sample 8526. Markalak clay. Top: Cumulative sum. Bottom: Grain size classes. 

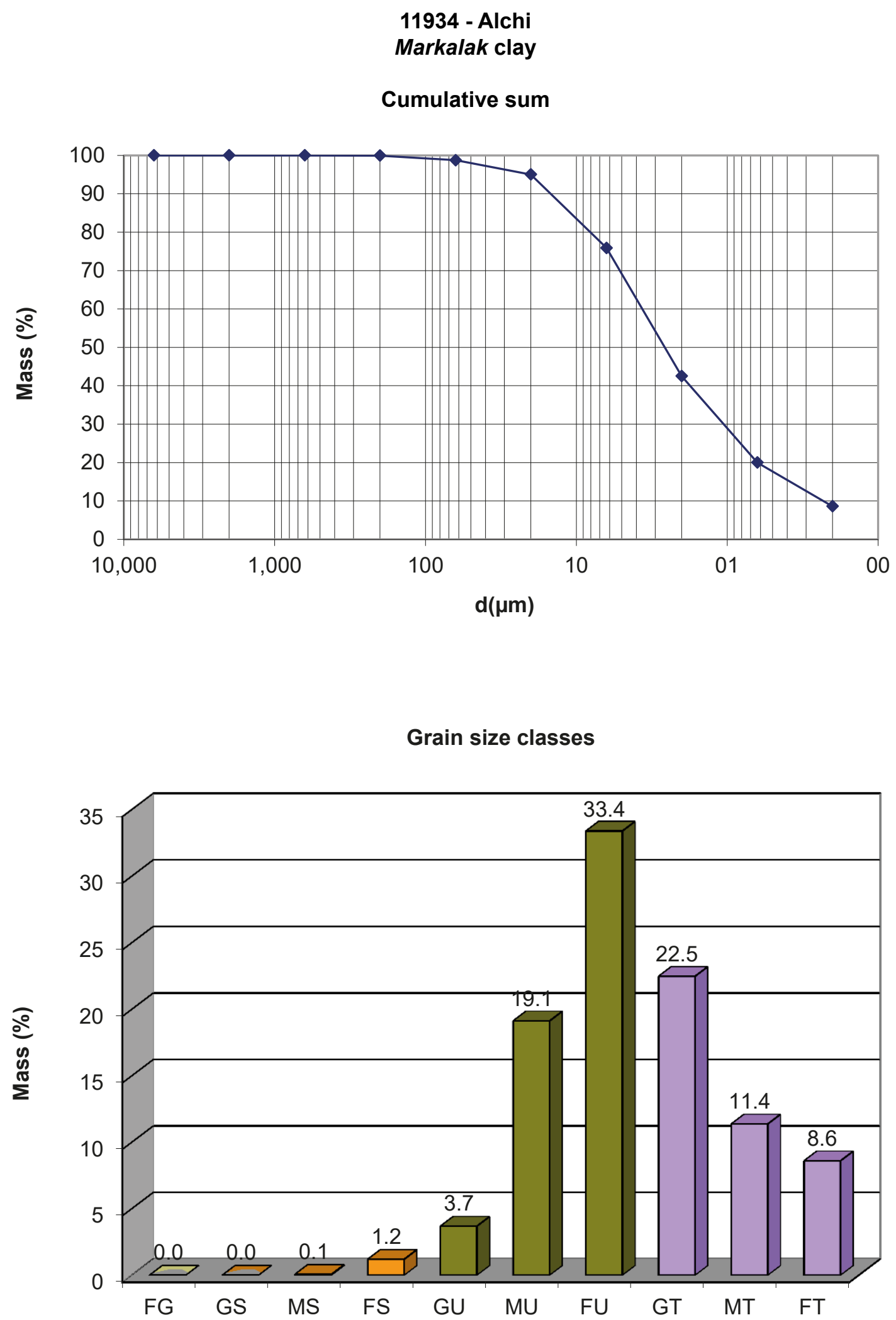

GSD 6.4 Alchi. Sample 11934. Markalak clay. Top: Cumulative sum. Bottom: Grain size classes. 


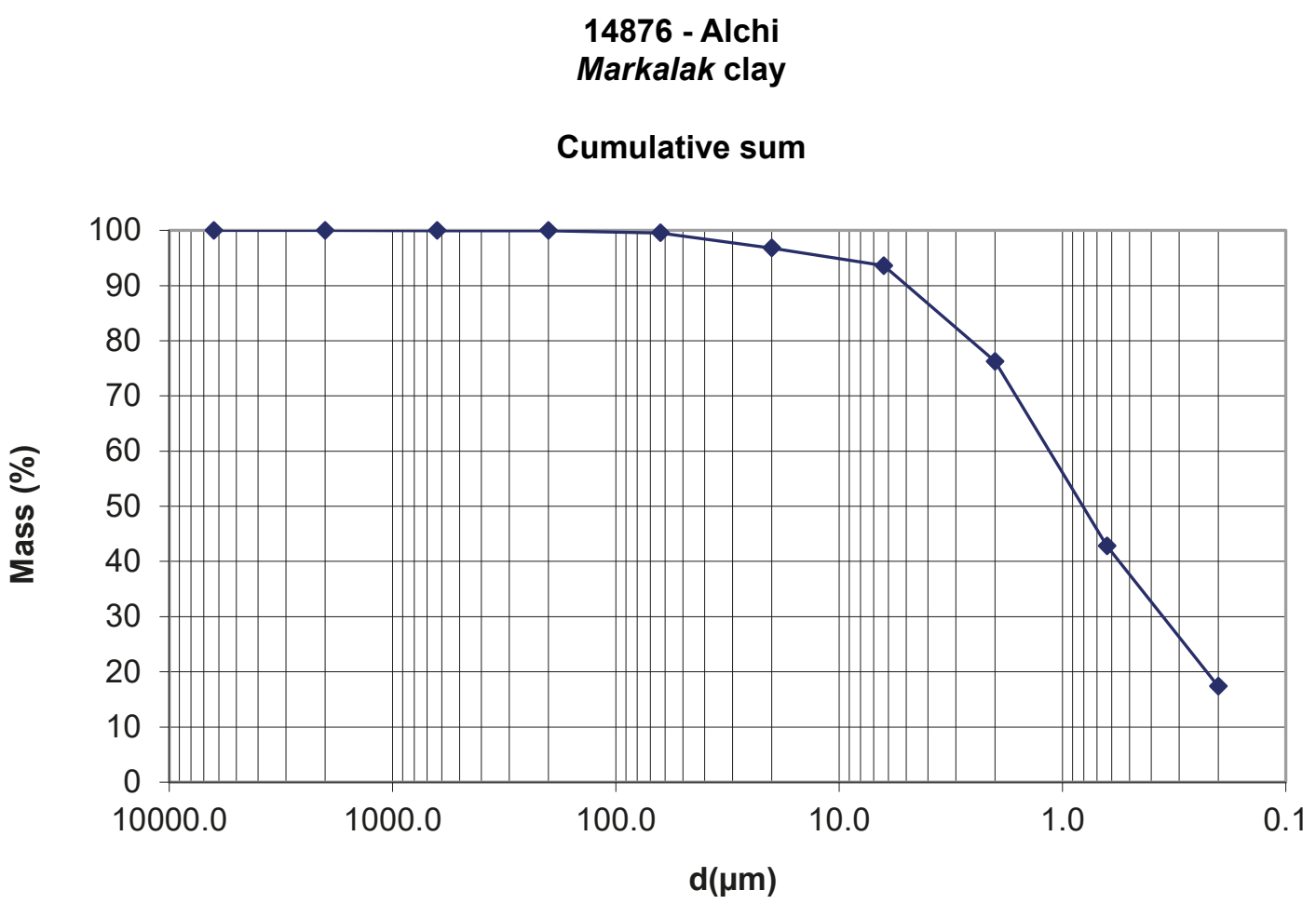

Grain size classes

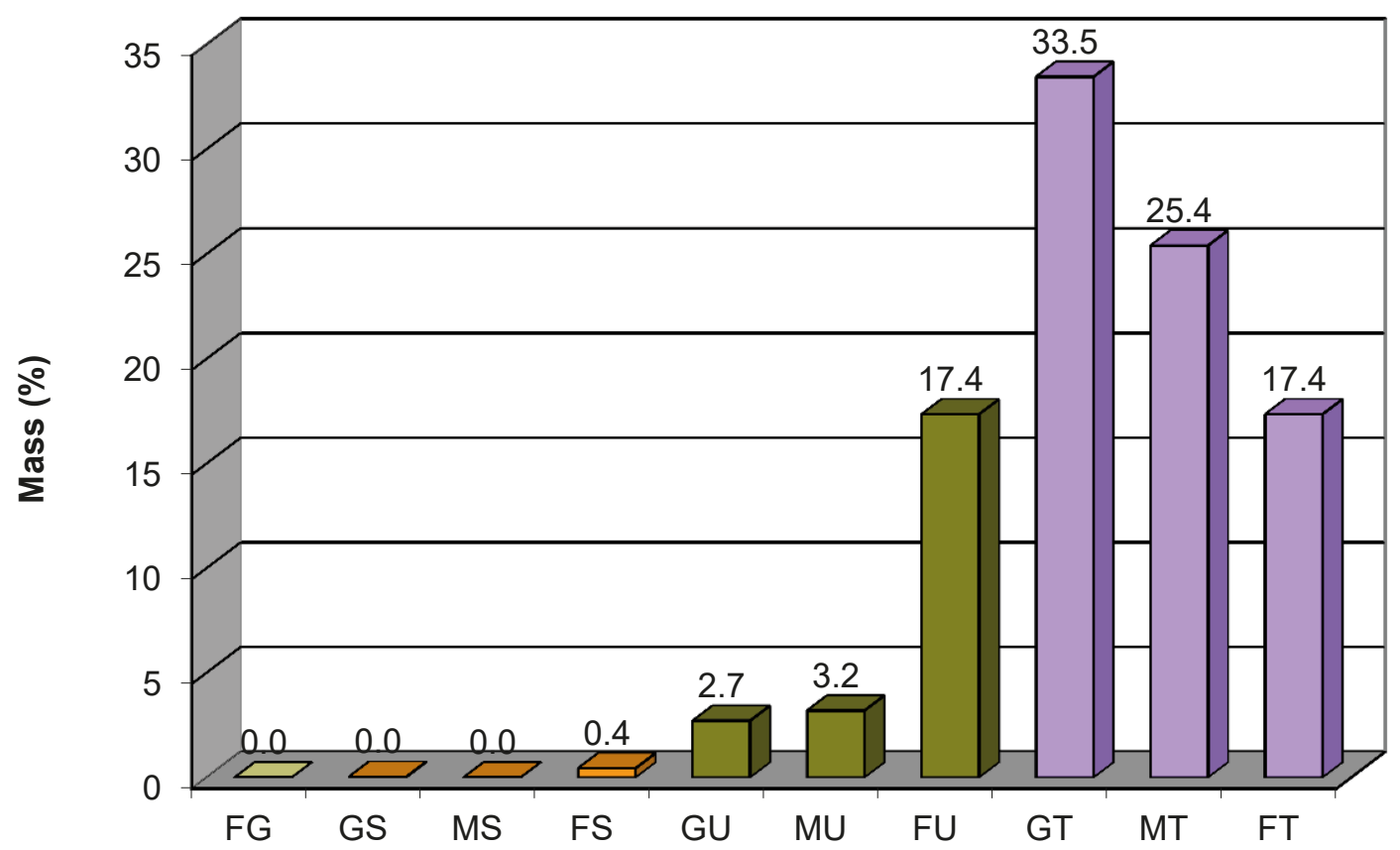

GSD 7.4 Alchi. Sample 14876. Markalak clay. Top: Cumulative sum. Bottom: Grain size classes. 
11939 - Lamayuru

Markalak clay

\section{Cumulative sum}

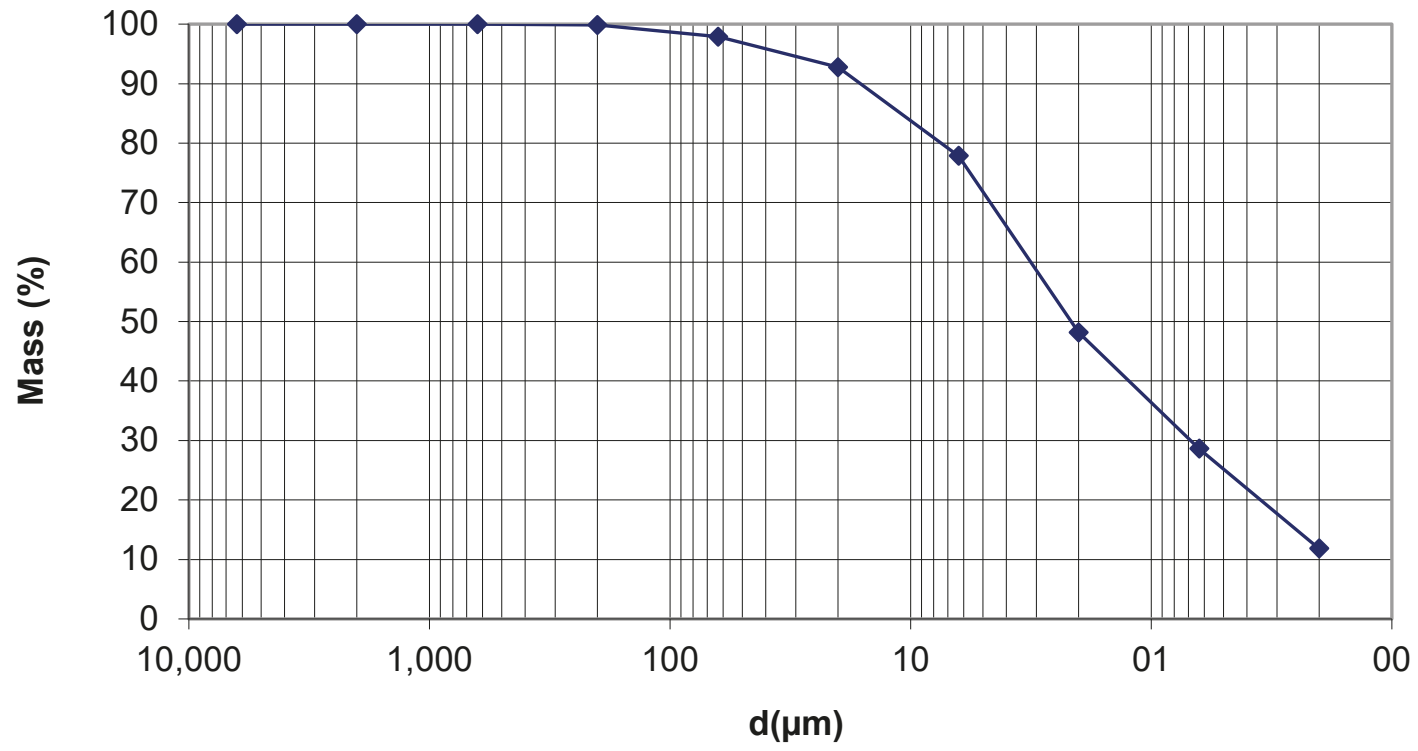

Grain size classes

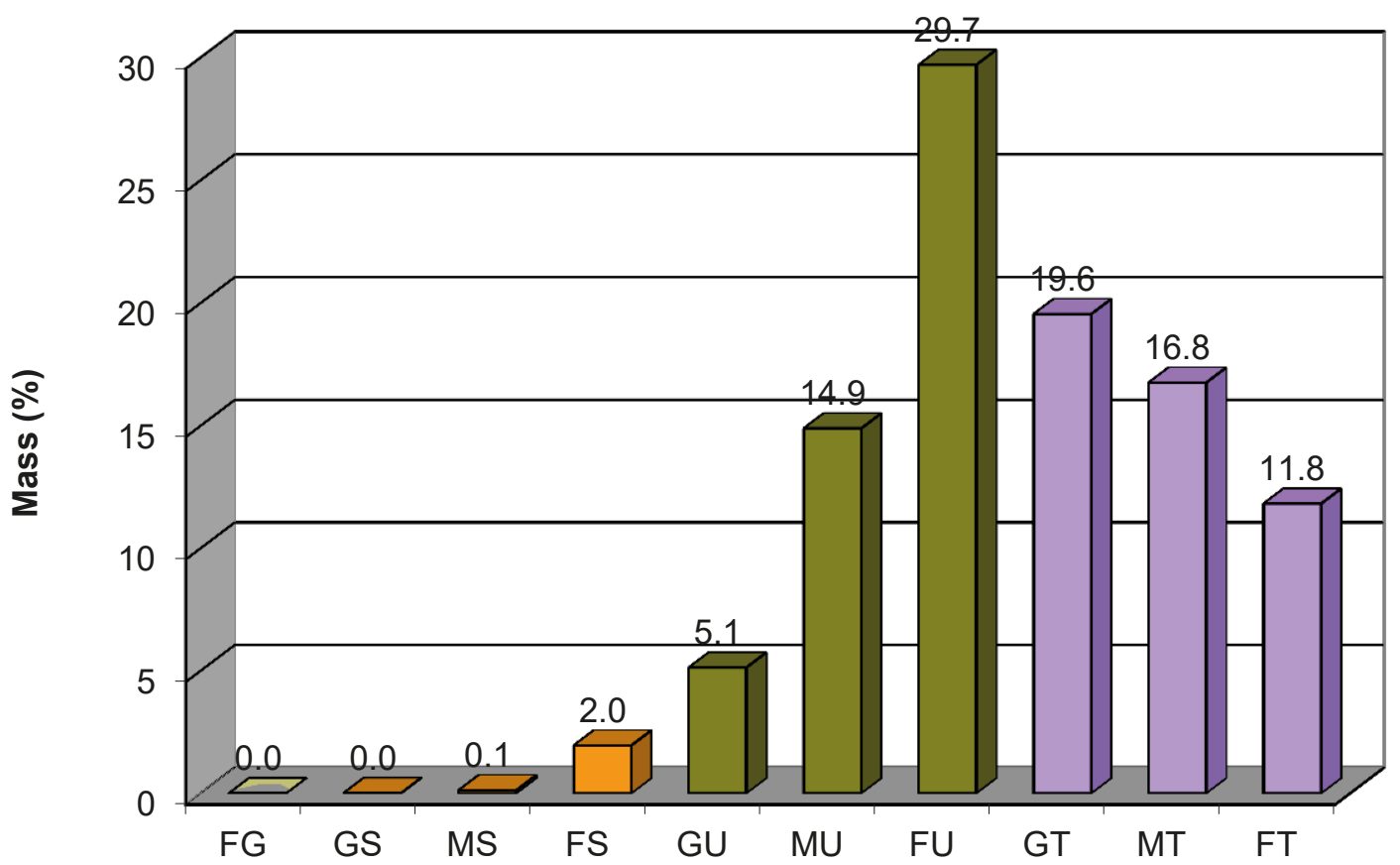

GSD 8.4 Lamayuru. Sample 11939. Markalak clay. Top: Cumulative sum. Bottom: Grain size classes. 

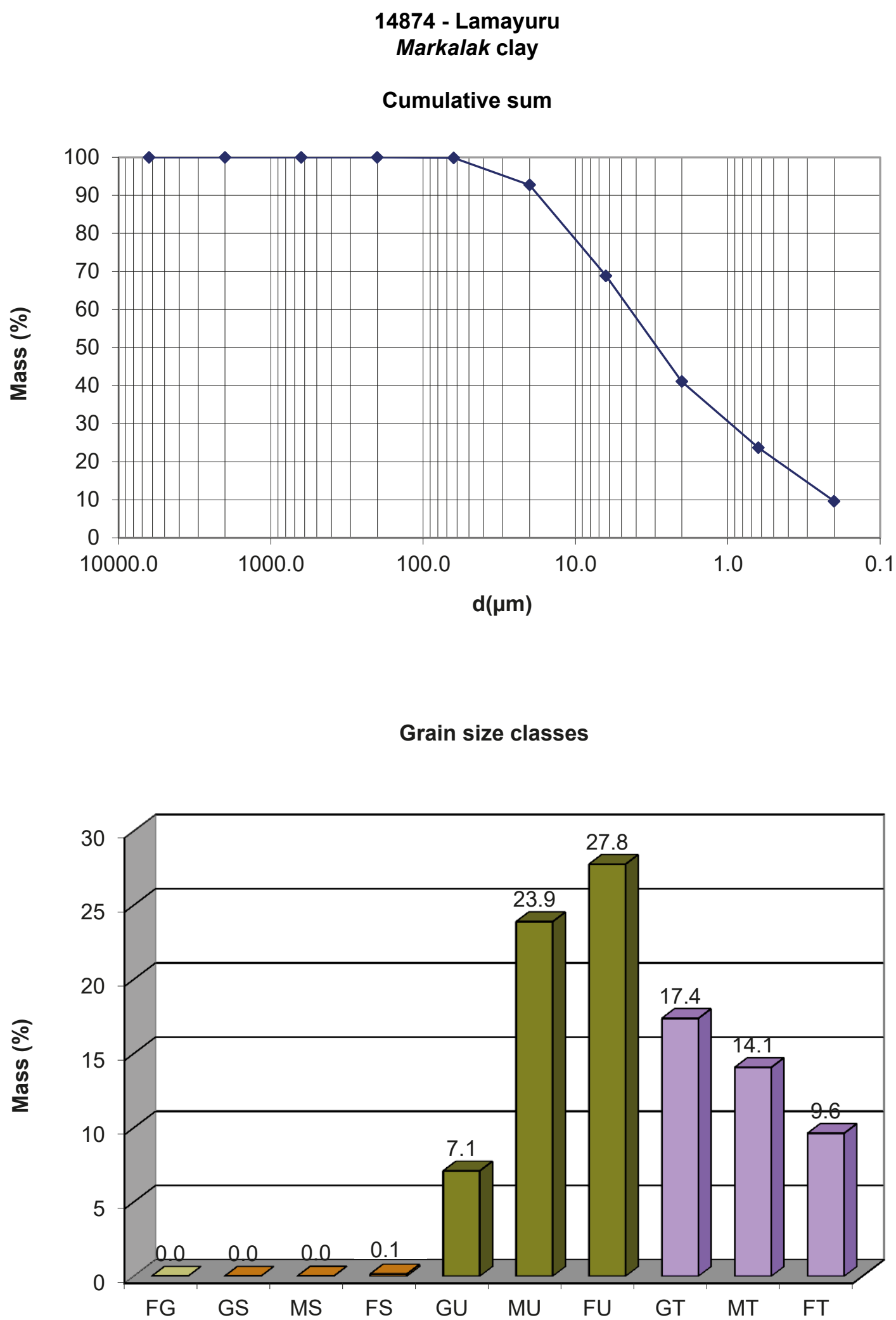

GSD 9.4 Lamayuru. Sample 14874. Markalak clay. Top: Cumulative sum. Bottom: Grain size classes. 


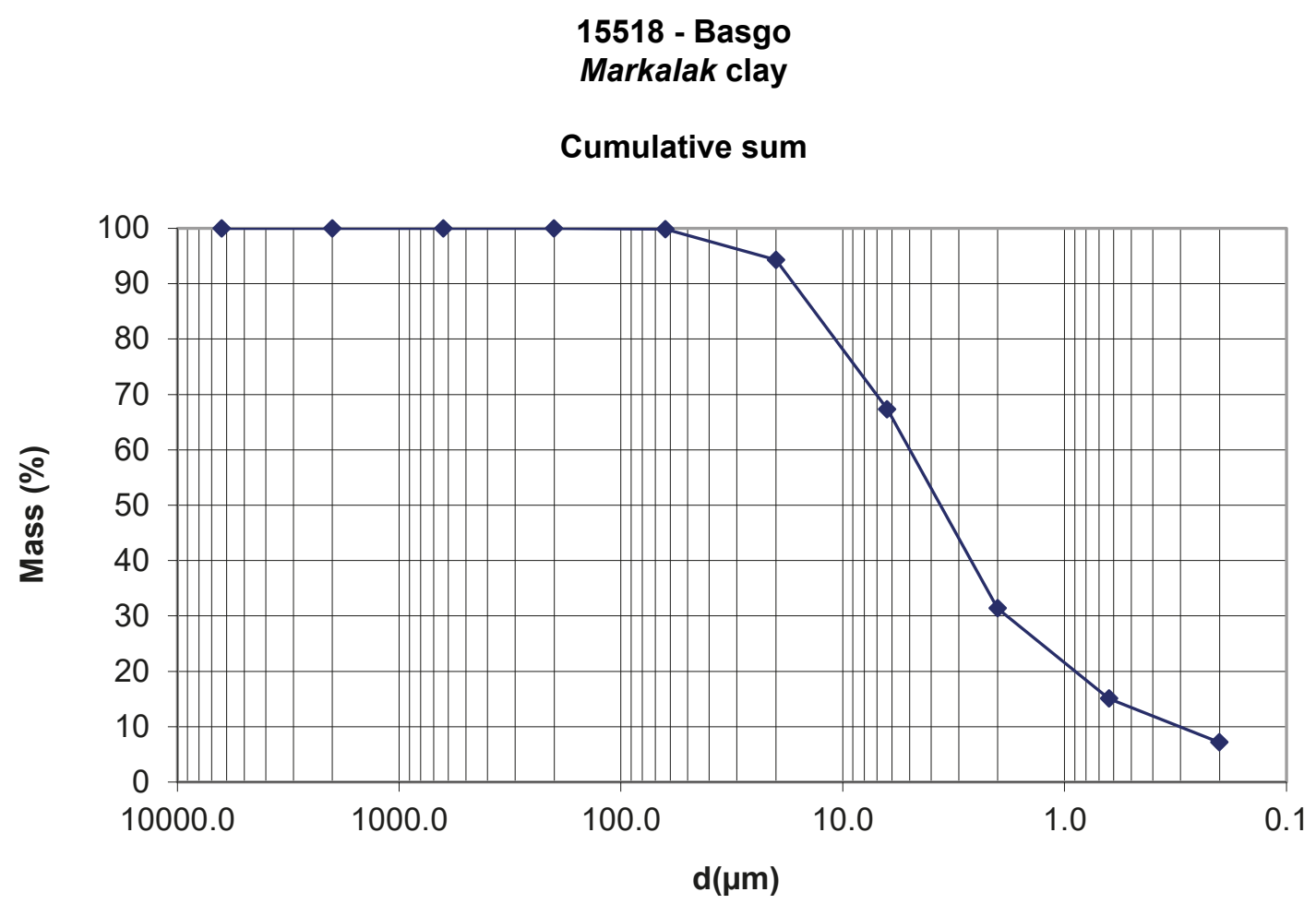

Grain size classes

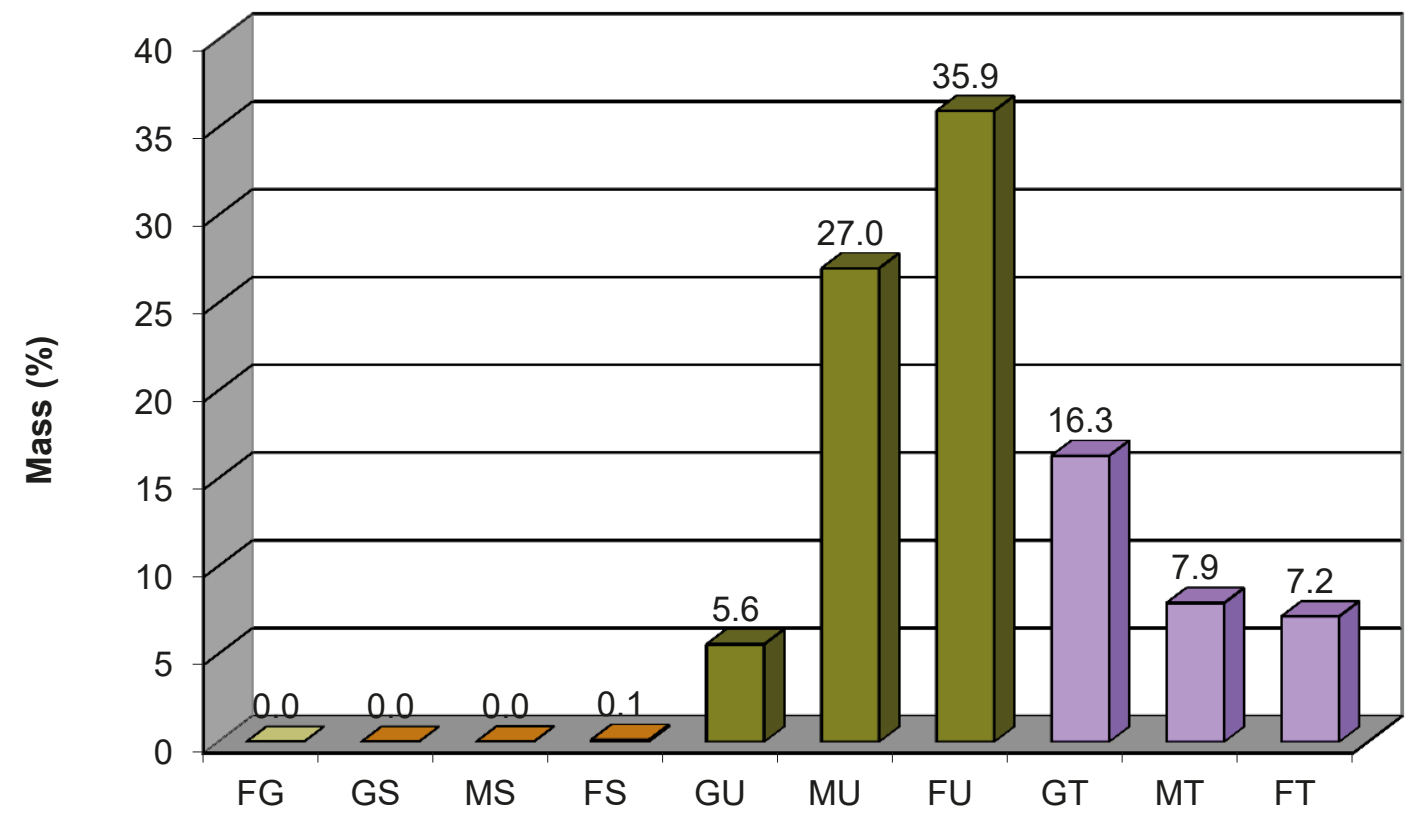

GSD 10.4 Basgo. Sample 15518. Markalak clay. Top: Cumulative sum. Bottom: Grain size classes. 

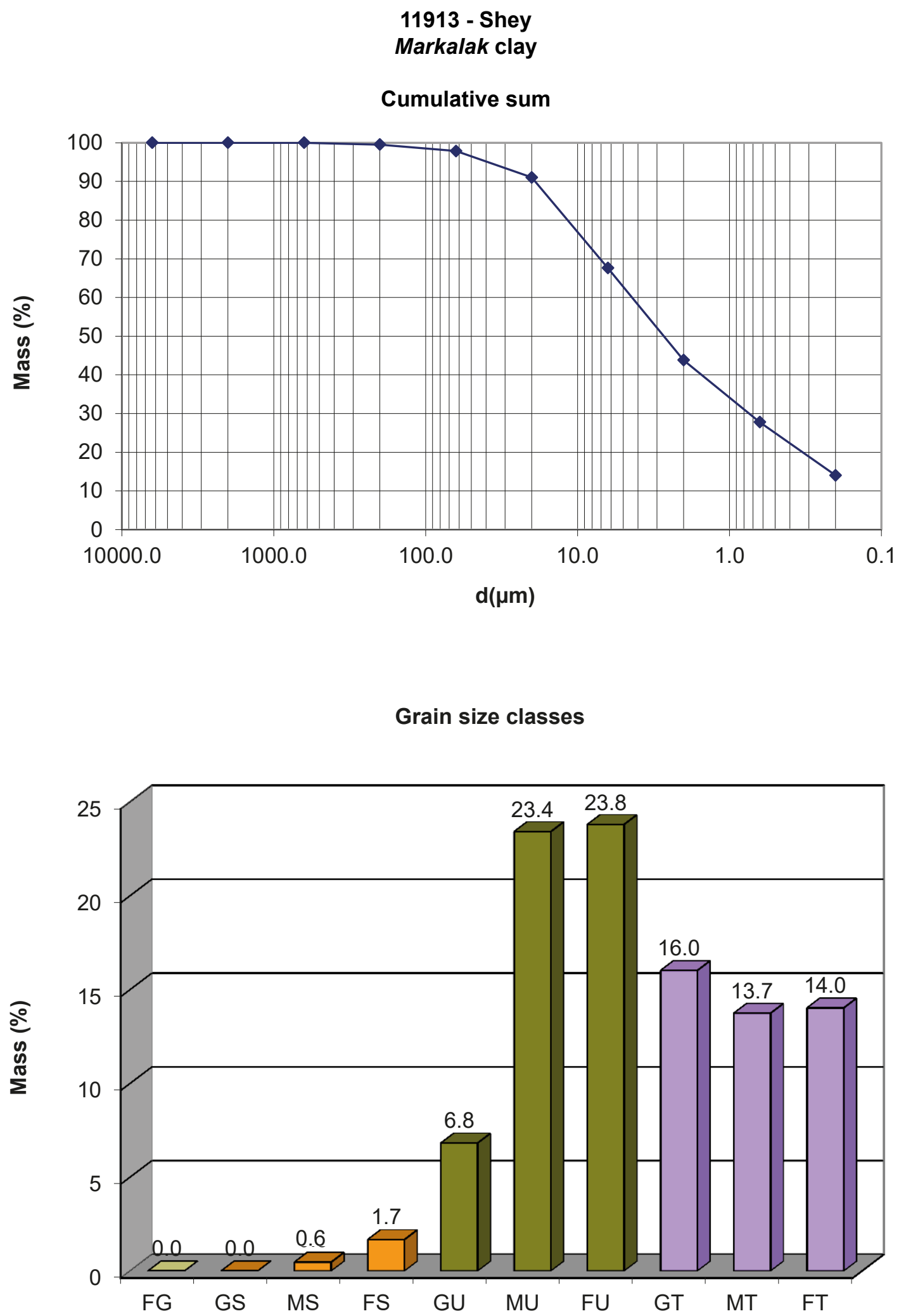

GSD 11.4 Shey. Sample 11913. Markalak clay. Top: Cumulative sum. Bottom: Grain size classes. 


\section{4 - Shey \\ Clay pit - raw material for bricks}

Cumulative sum

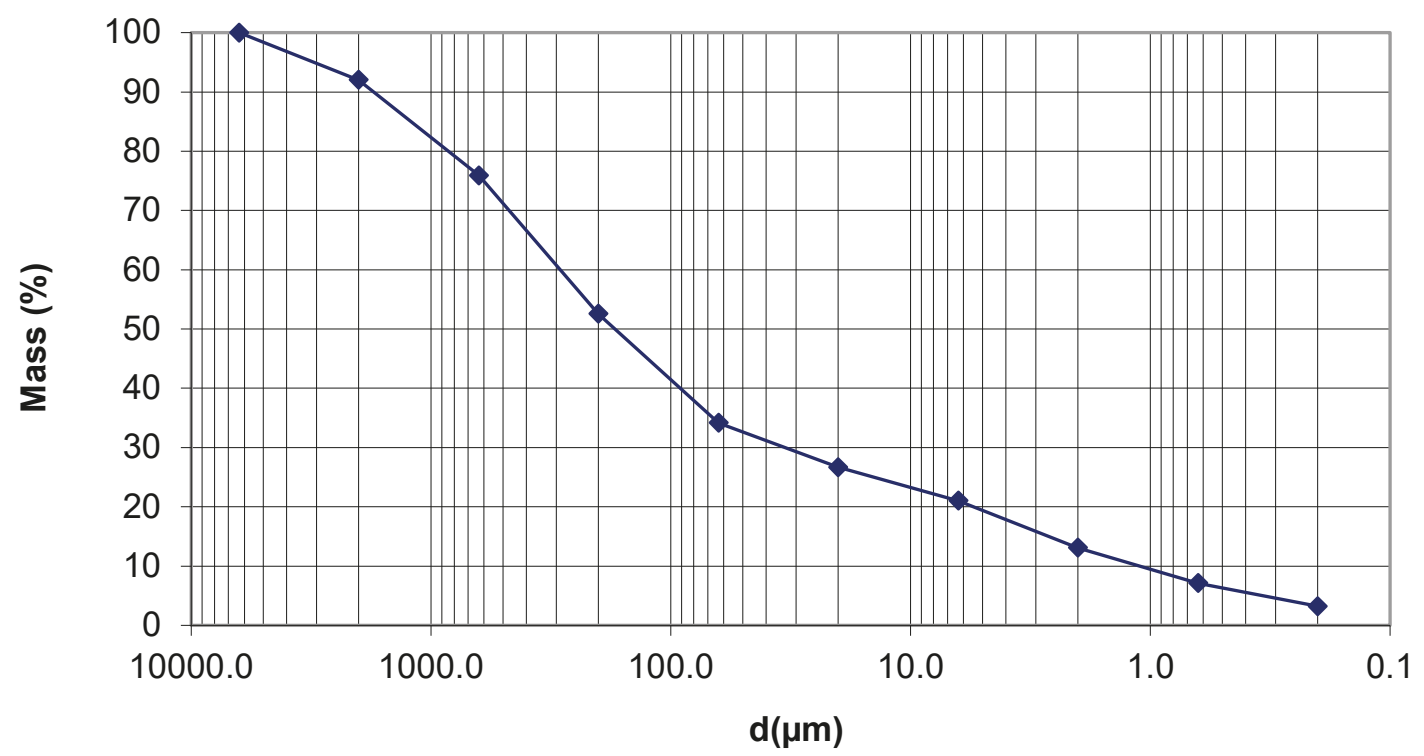

Grain size classes

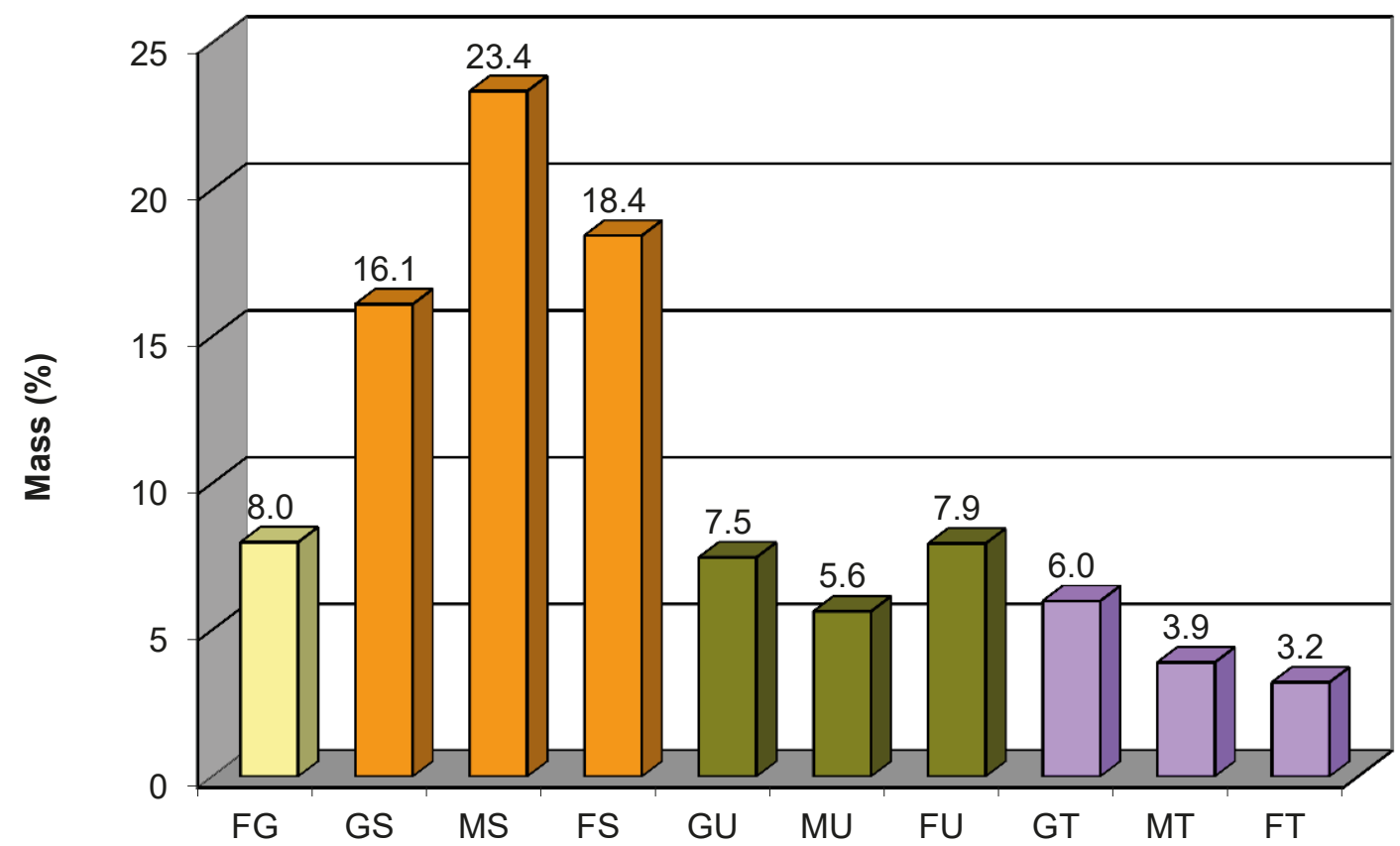

GSD 12.4 Shey. Sample 15404. Clay pit. Raw material for bricks. Top: Cumulative sum. Bottom: Grain size classes. 
15516 - Nako

Tua clay

Cumulative sum

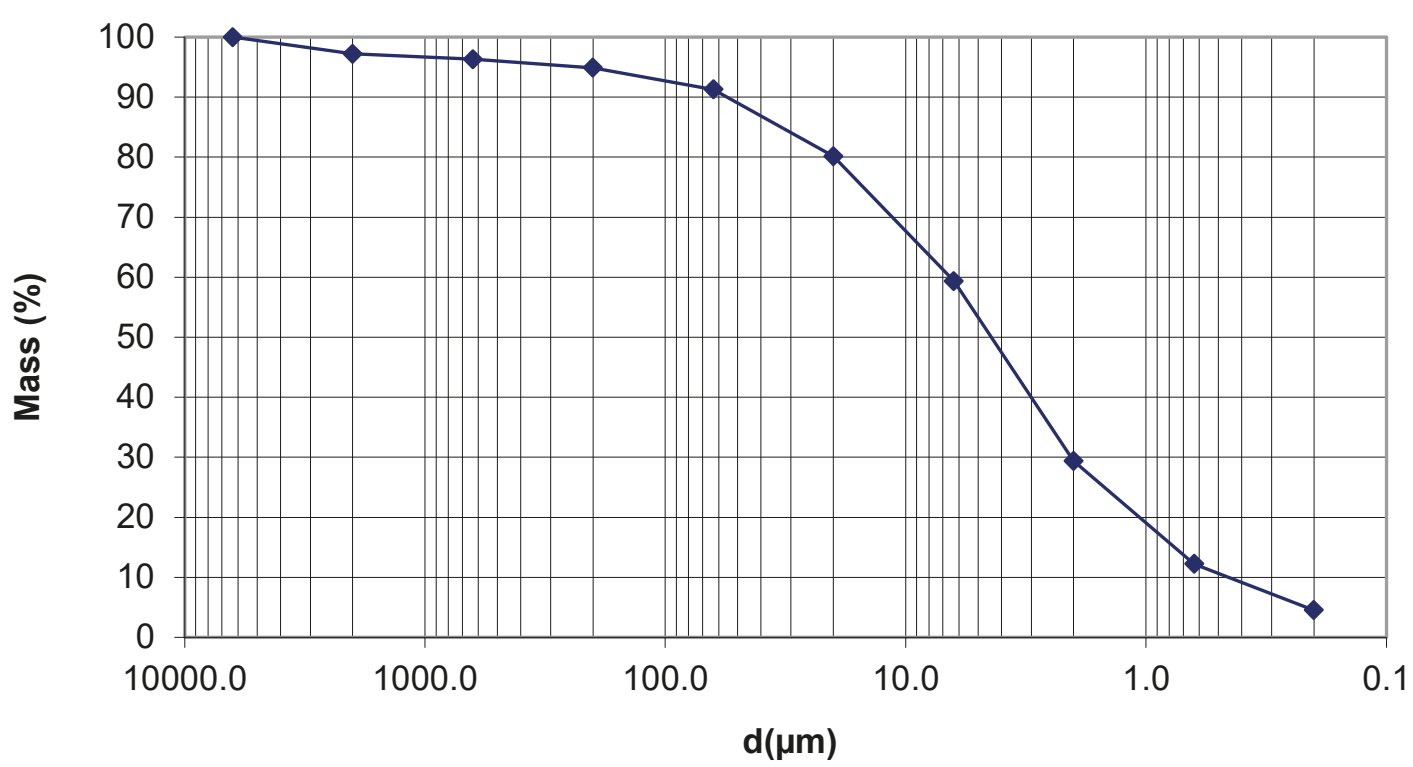

Grain size classes

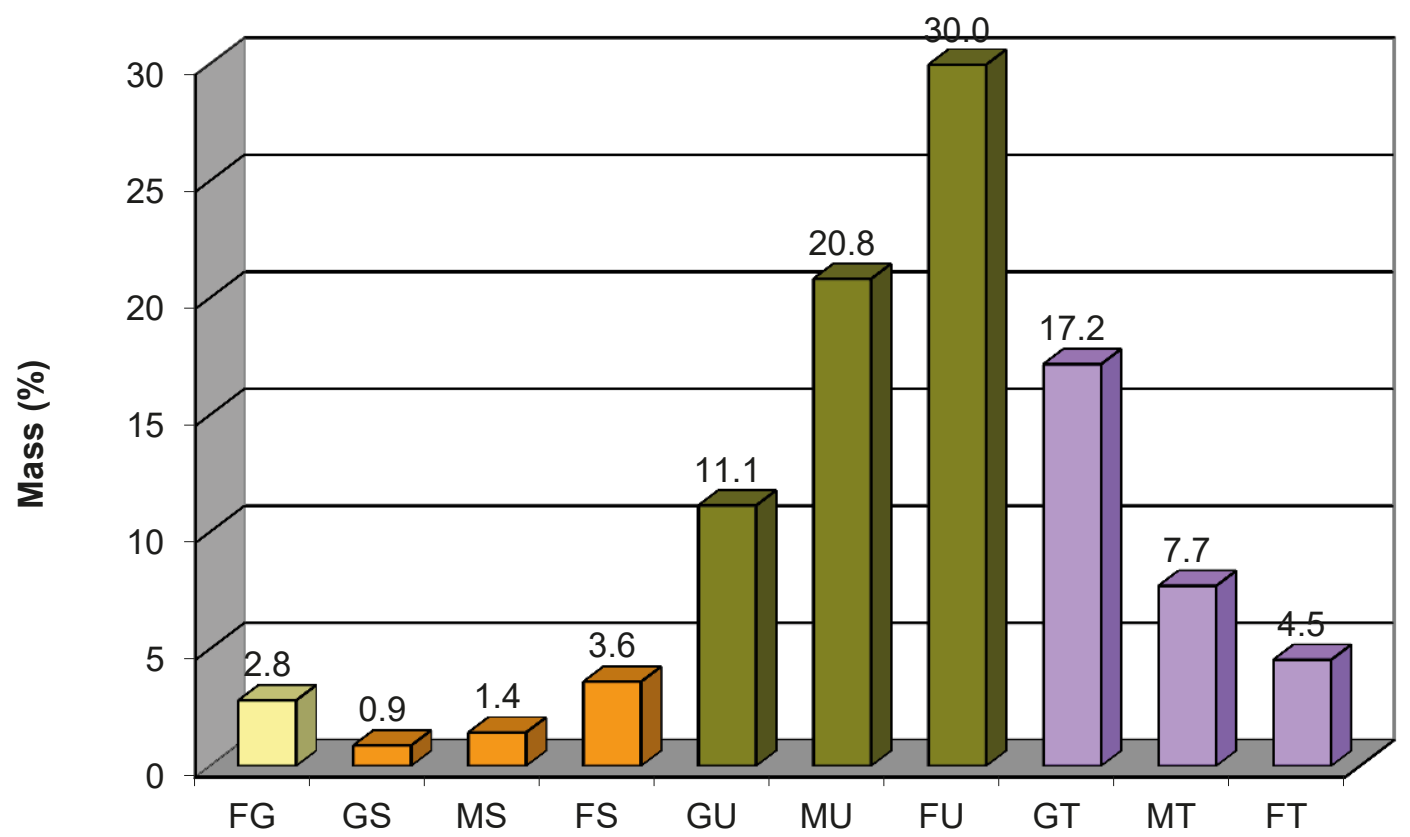

GSD 13.4 Nako. Sample 15516. Tua clay. Top: Cumulative sum. Bottom: Grain size classes. 
8504 - Shelkhar

Tua clay

Cumulative sum

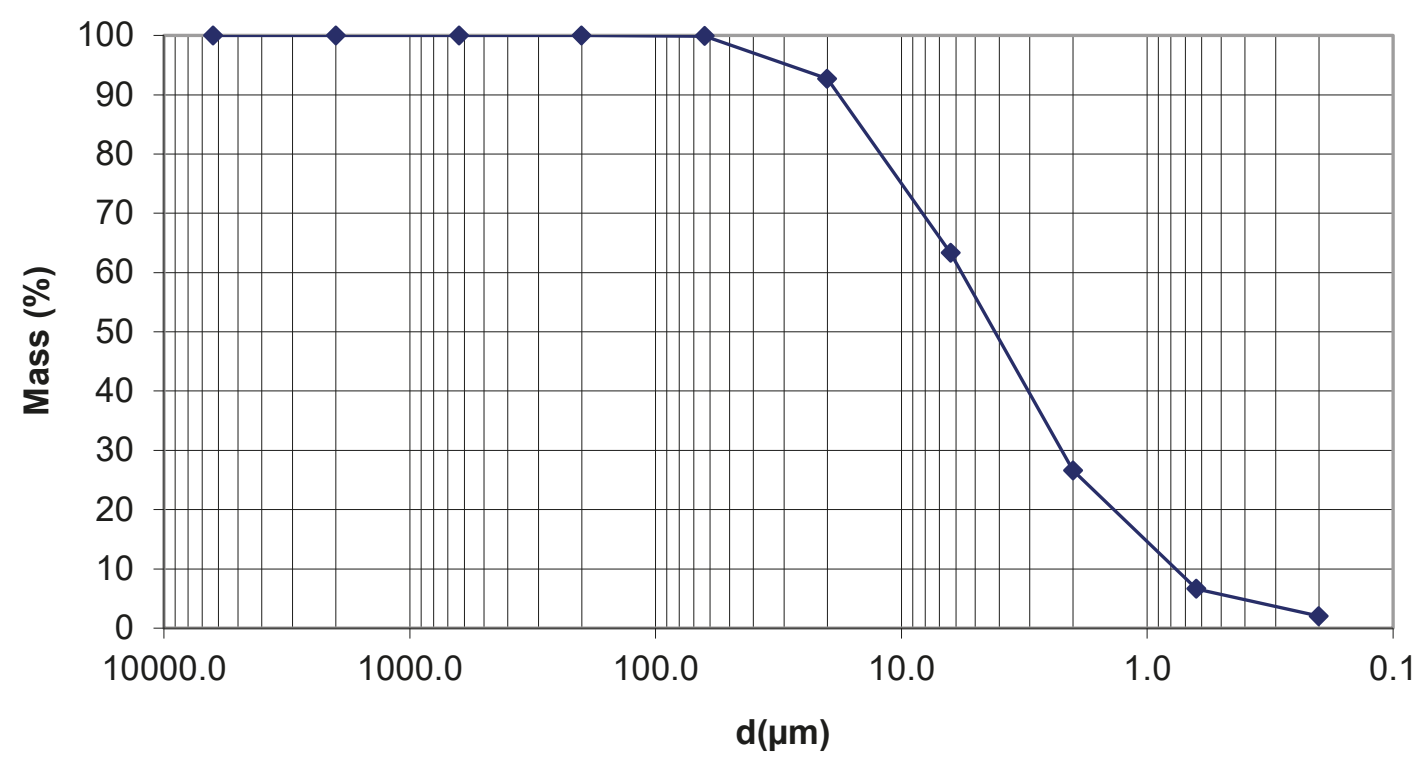

Grain size classes

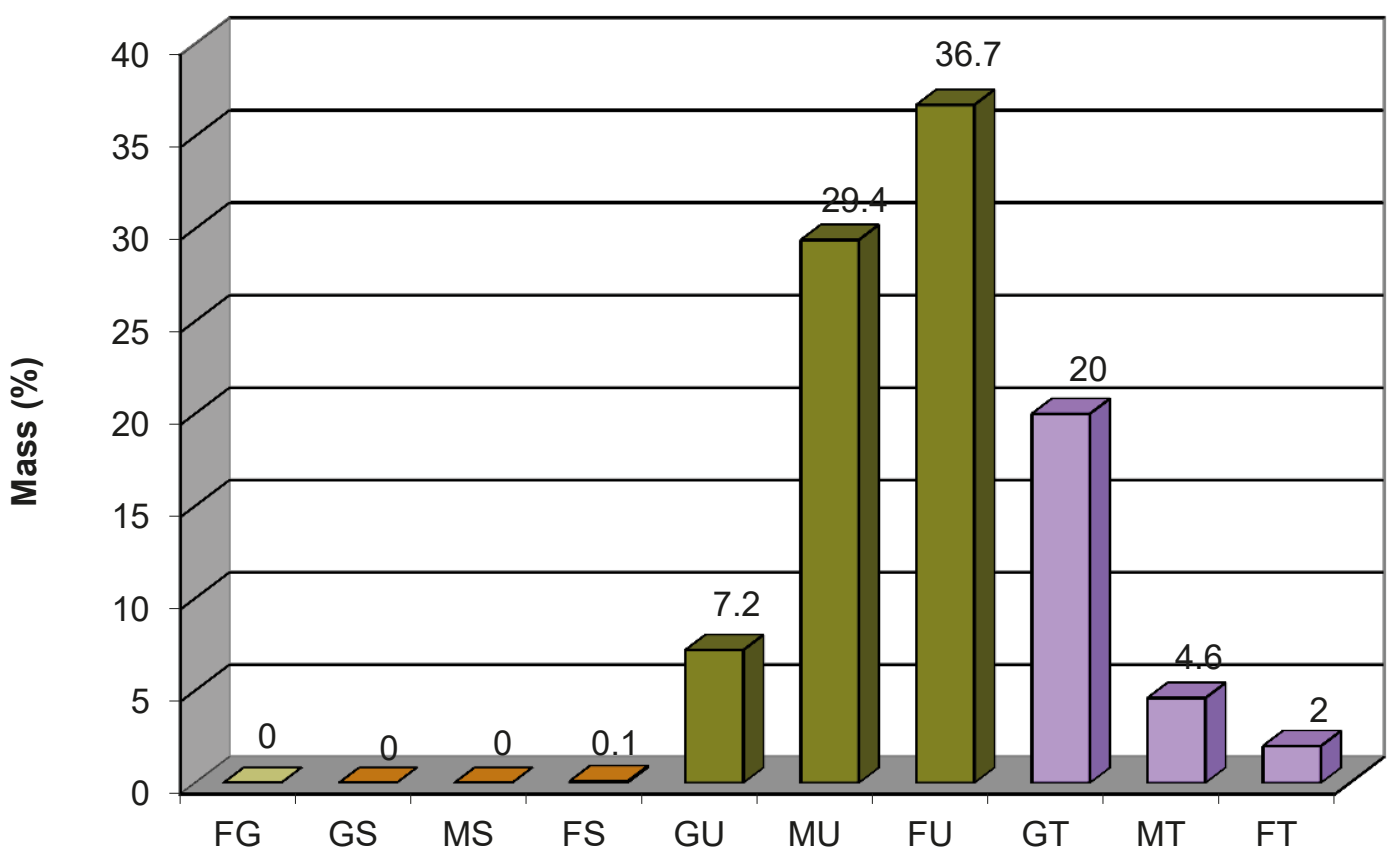

GSD 14.4 Shelkhar. Sample 8504. Tua clay. Top: Cumulative sum. Bottom: Grain size classes. 

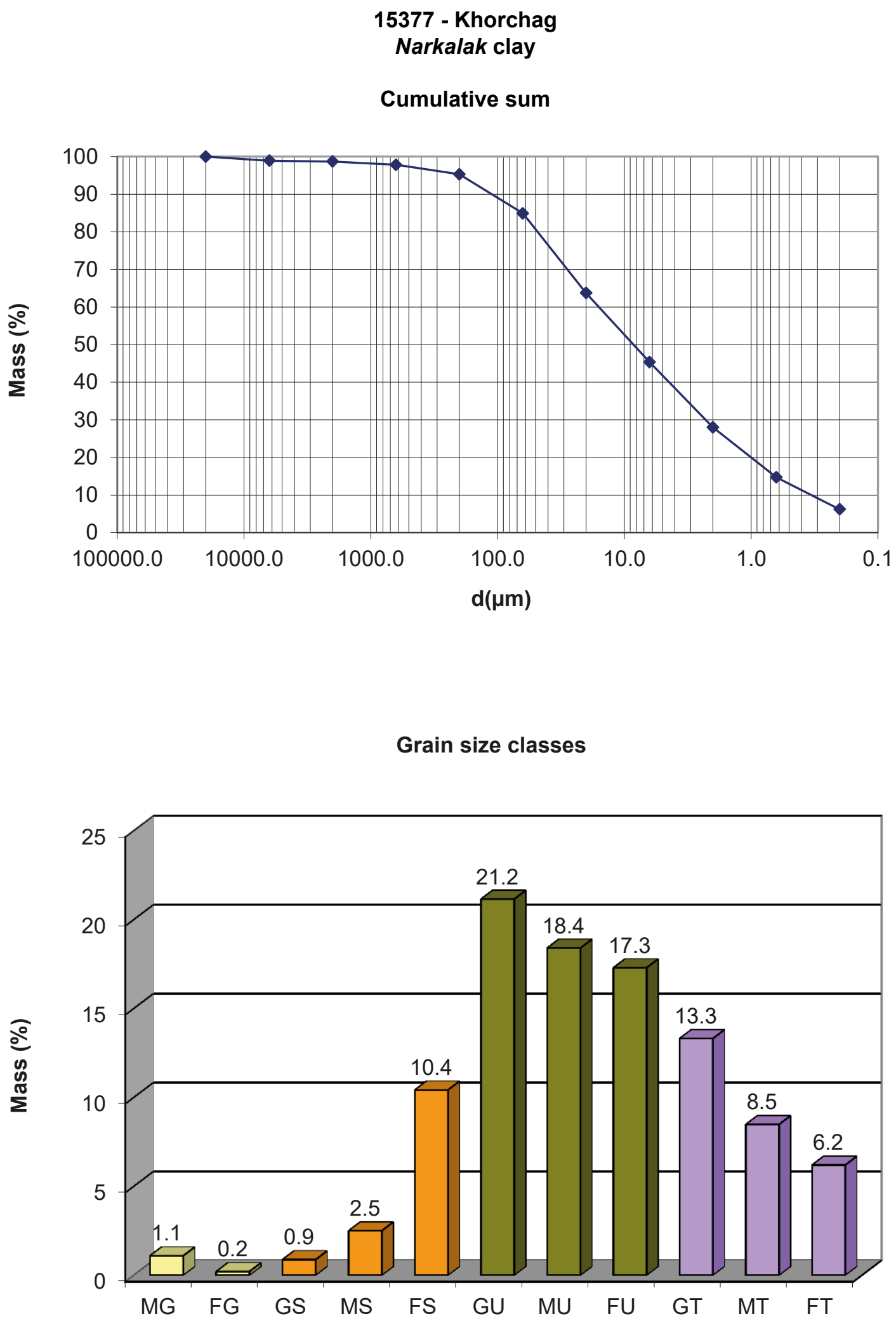

GSD 15.4 Khorchag. Sample 15377. Narkalak clay. Top: Cumulative sum. Bottom: Grain size classes. 
Spituk - markalak clay

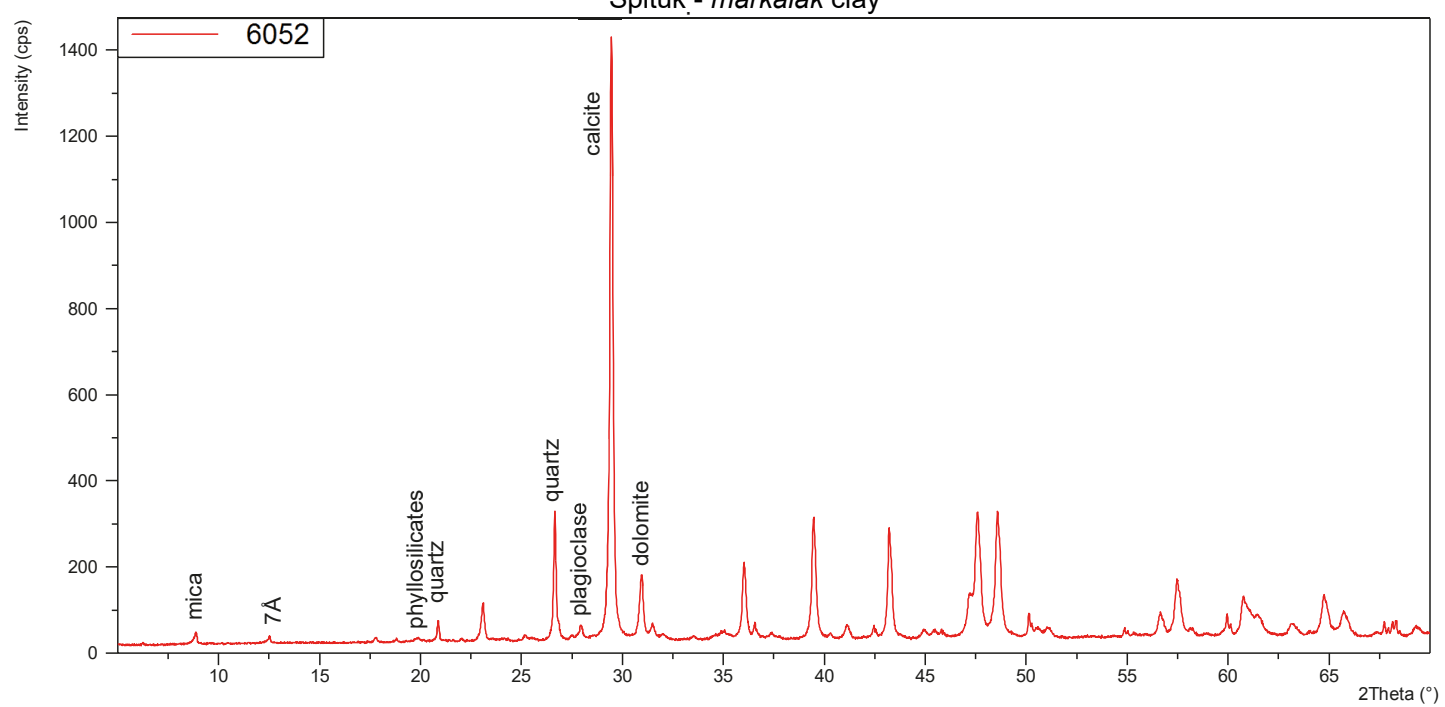

BMA 1.4 Spituk. Sample 6052. Markalak clay. Bulk mineral analysis.

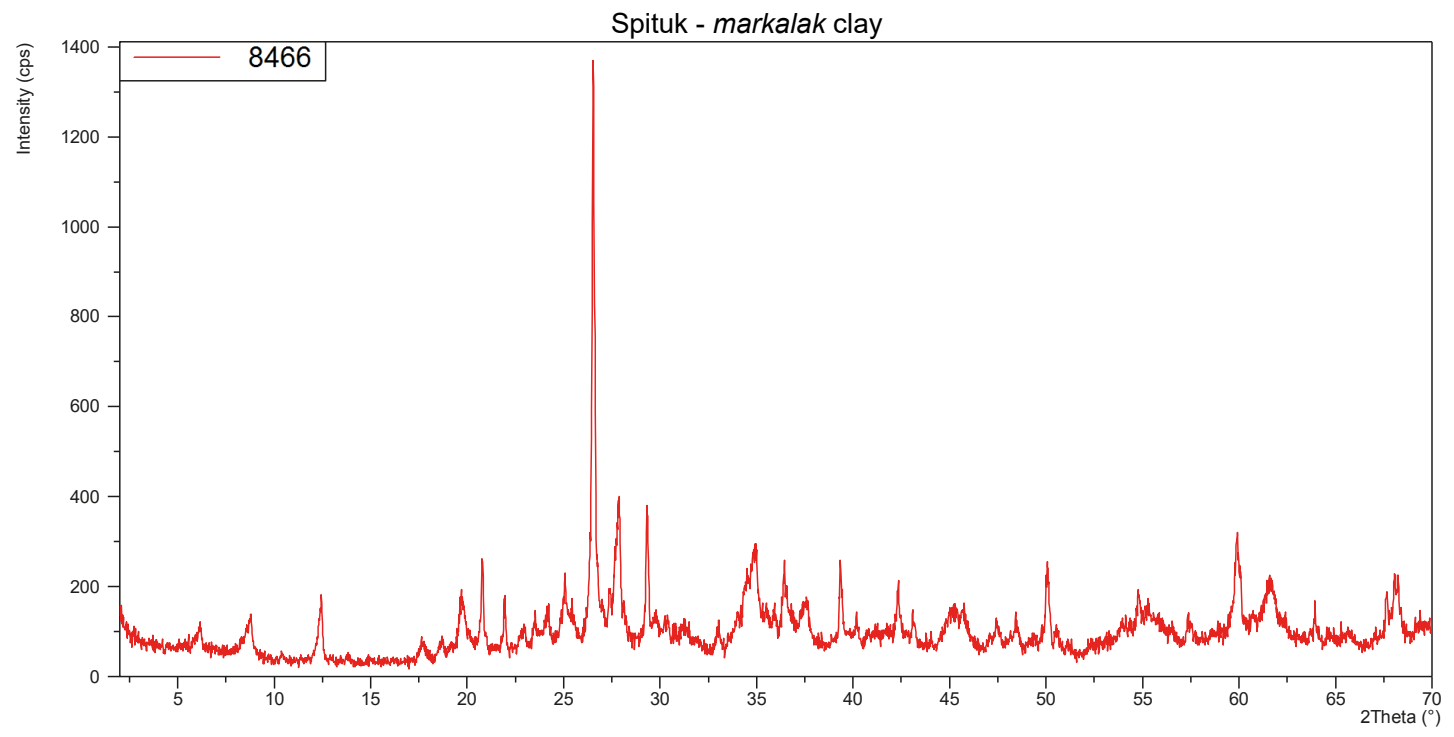

BMA 2.4 Spituk. Sample 8466. Markalak clay. Bulk mineral analysis. 
Spituk - markalak clay

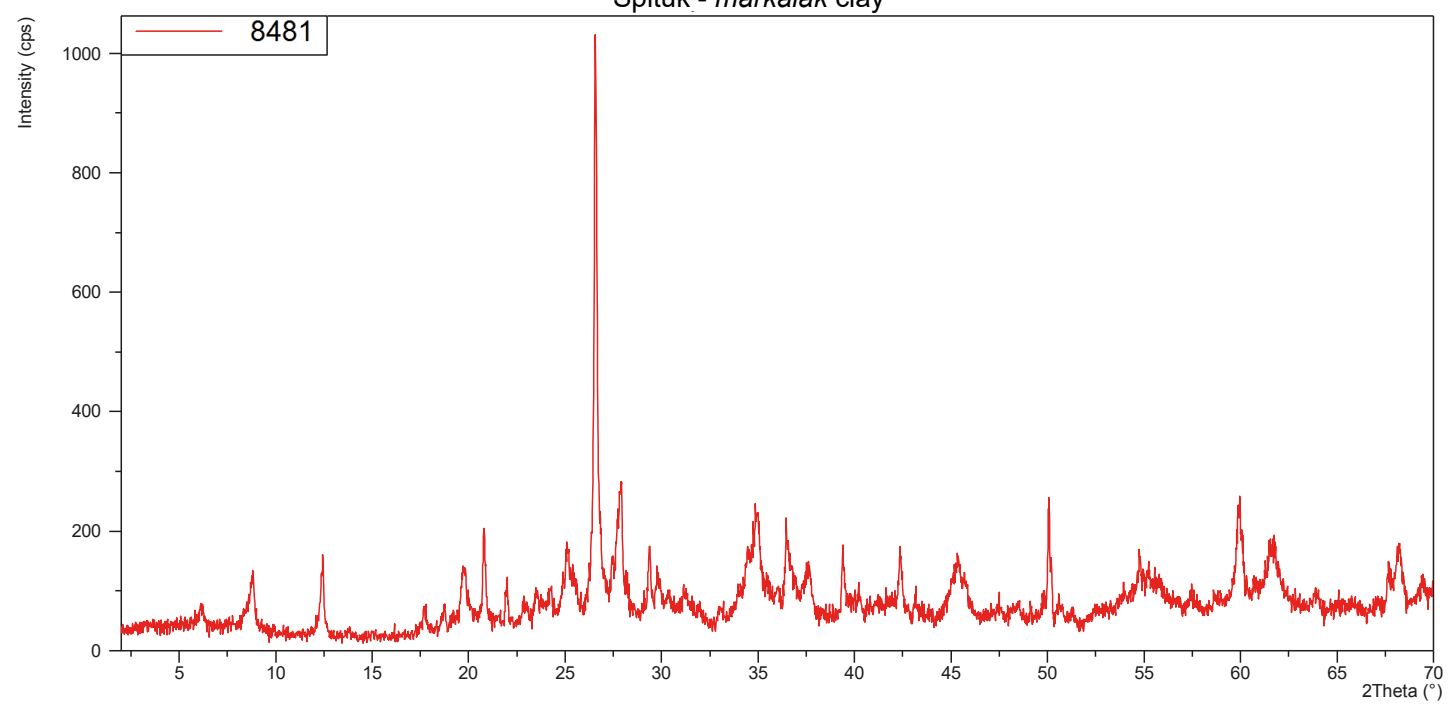

BMA 3.4 Spituk. Sample 8481. Markalak clay. Bulk mineral analysis.

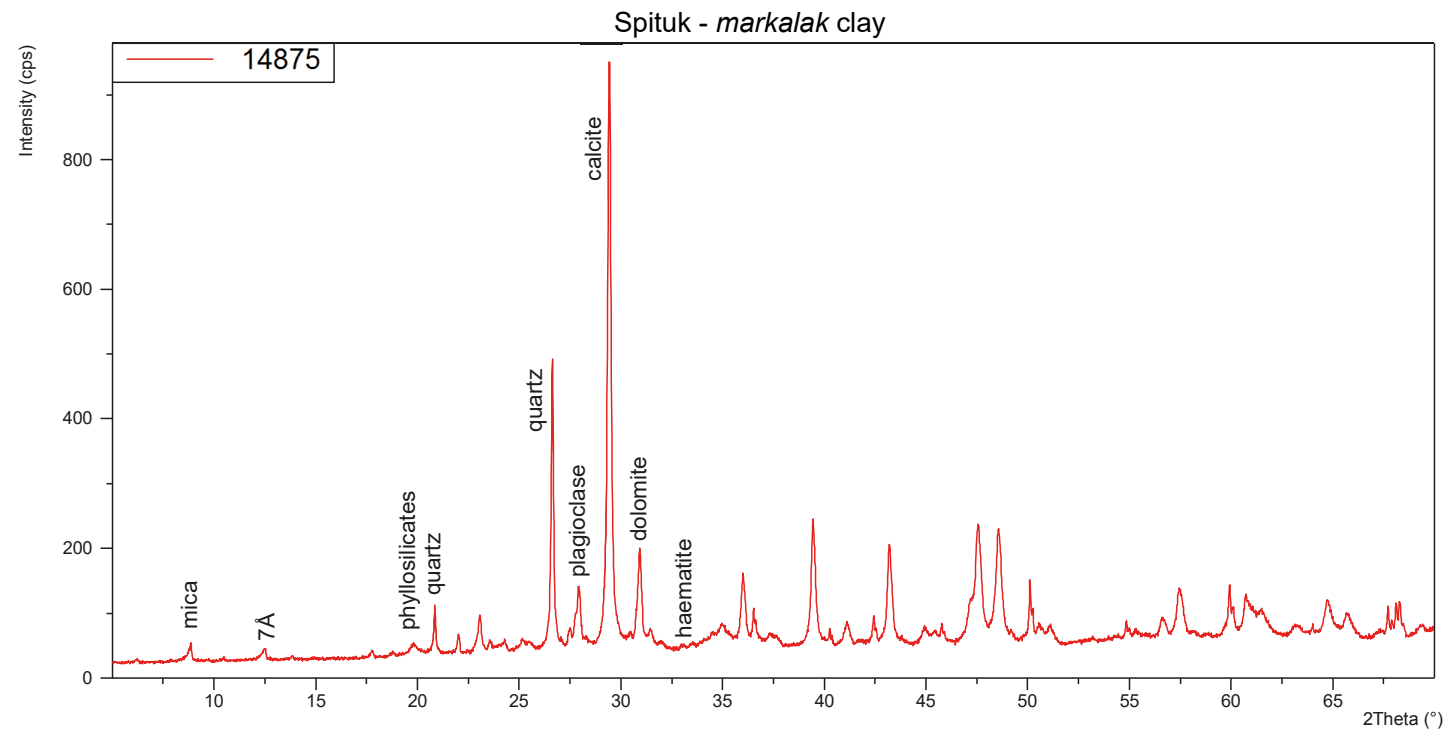

BMA 4.4 Khorchag. Sample 14875. Markalak clay. Bulk mineral analysis. 
Alchi - markalak clay

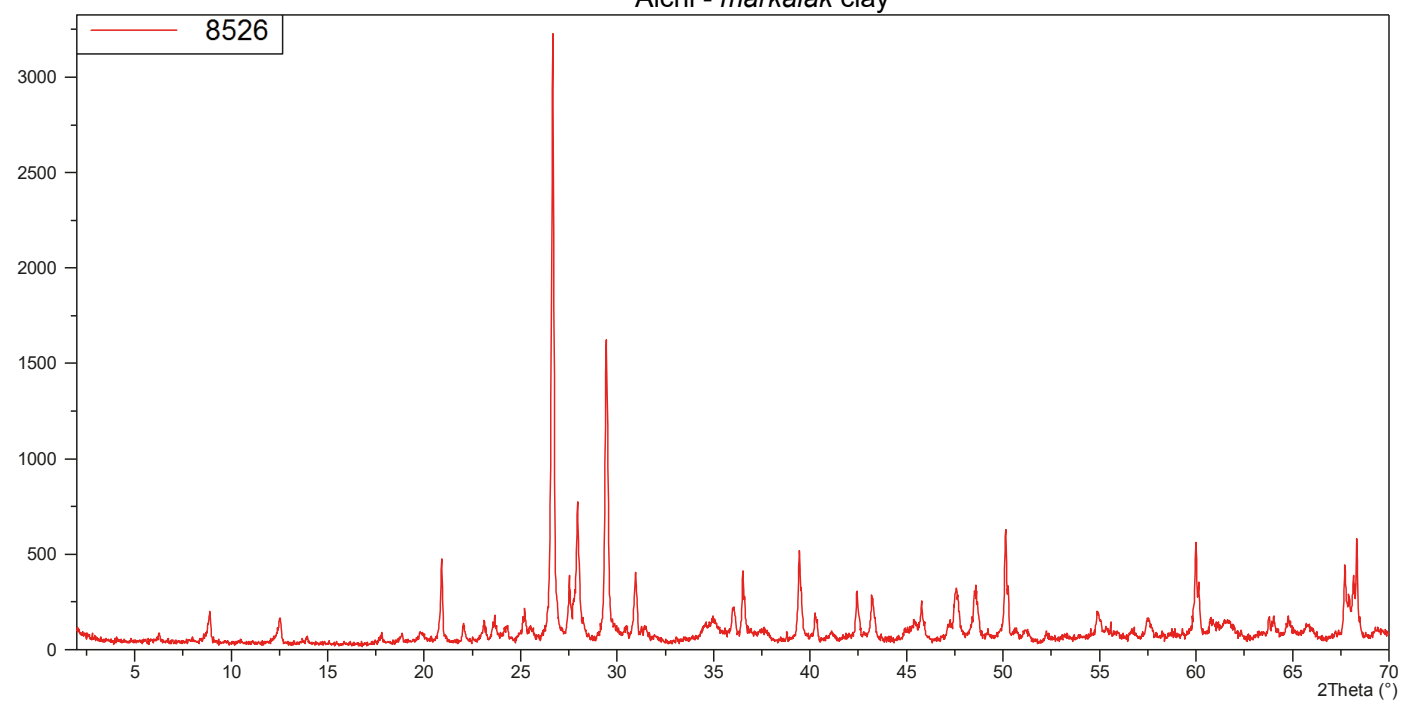

BMA 5.4 Alchi. Sample 8526. Markalak clay. Bulk mineral analysis.

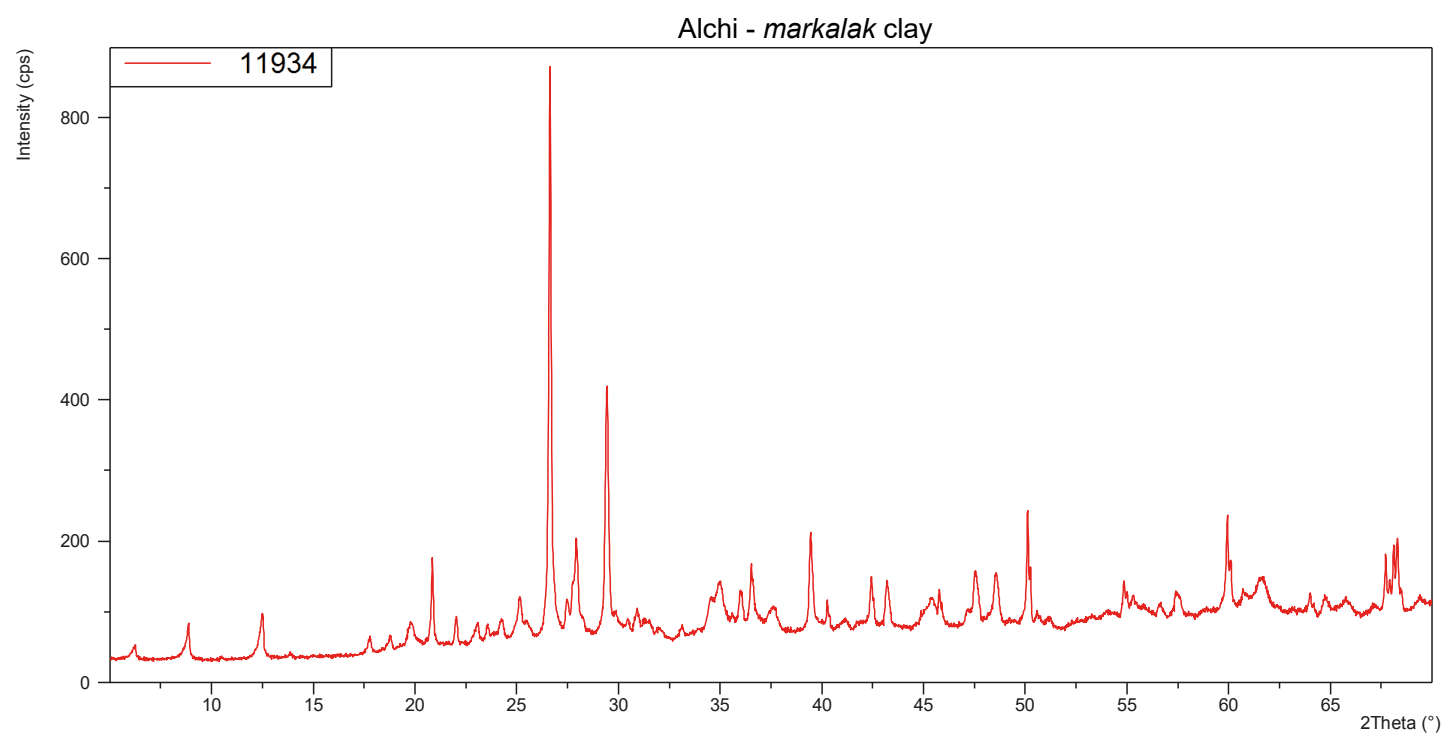

BMA 6.4 Alchi. Sample 11934. Markalak clay. Bulk mineral analysis. 


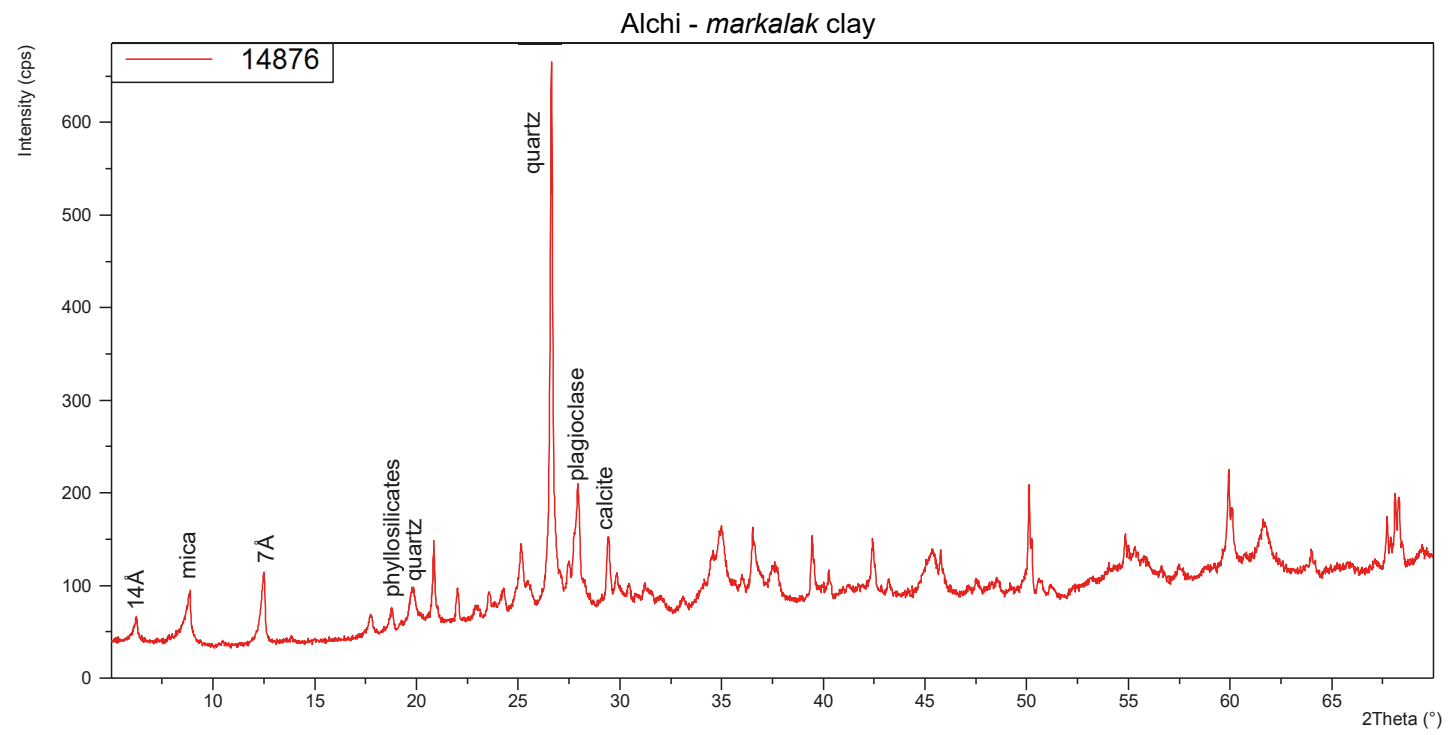

BMA 7.4 Alchi. Sample 14876. Markalak clay. Bulk mineral analysis.

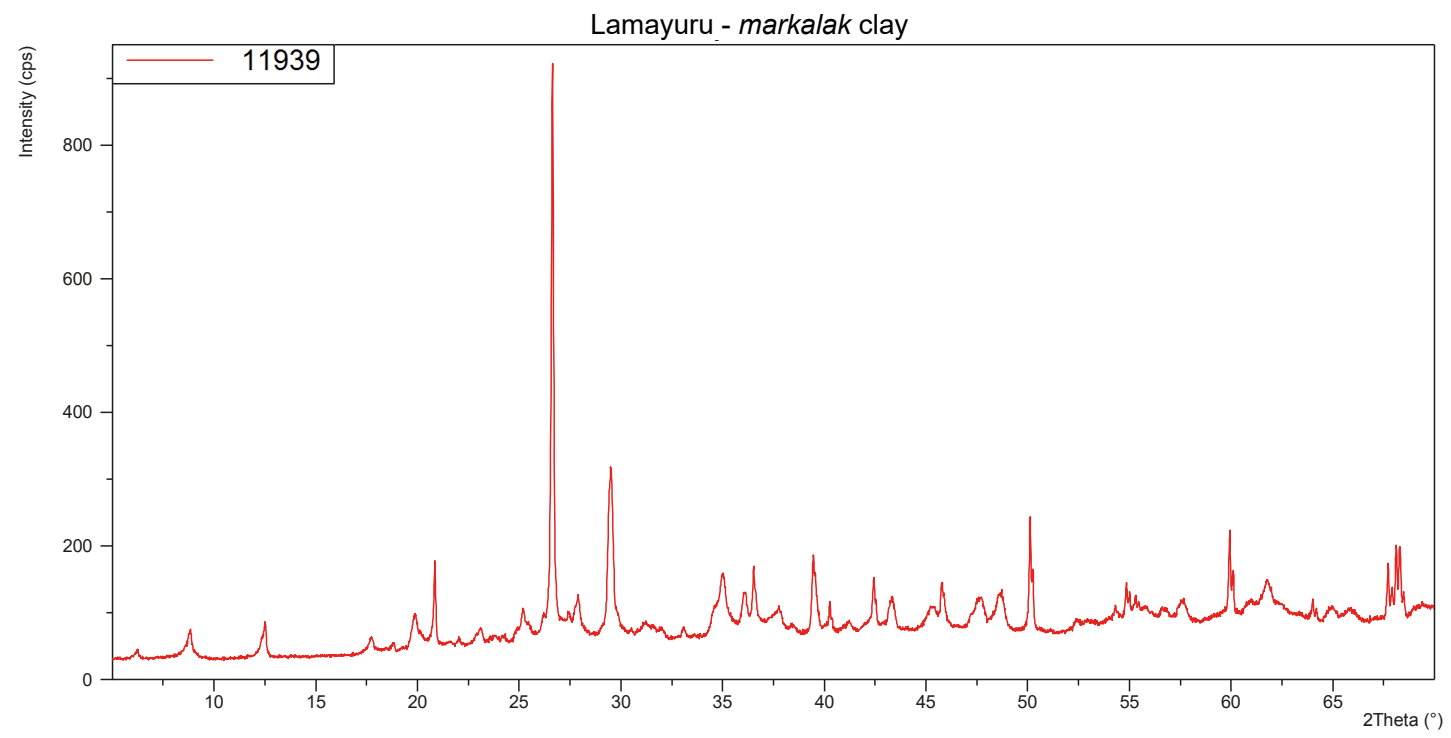

BMA 8.4 Lamayuru. Sample 11939. Markalak clay. Bulk mineral analysis. 


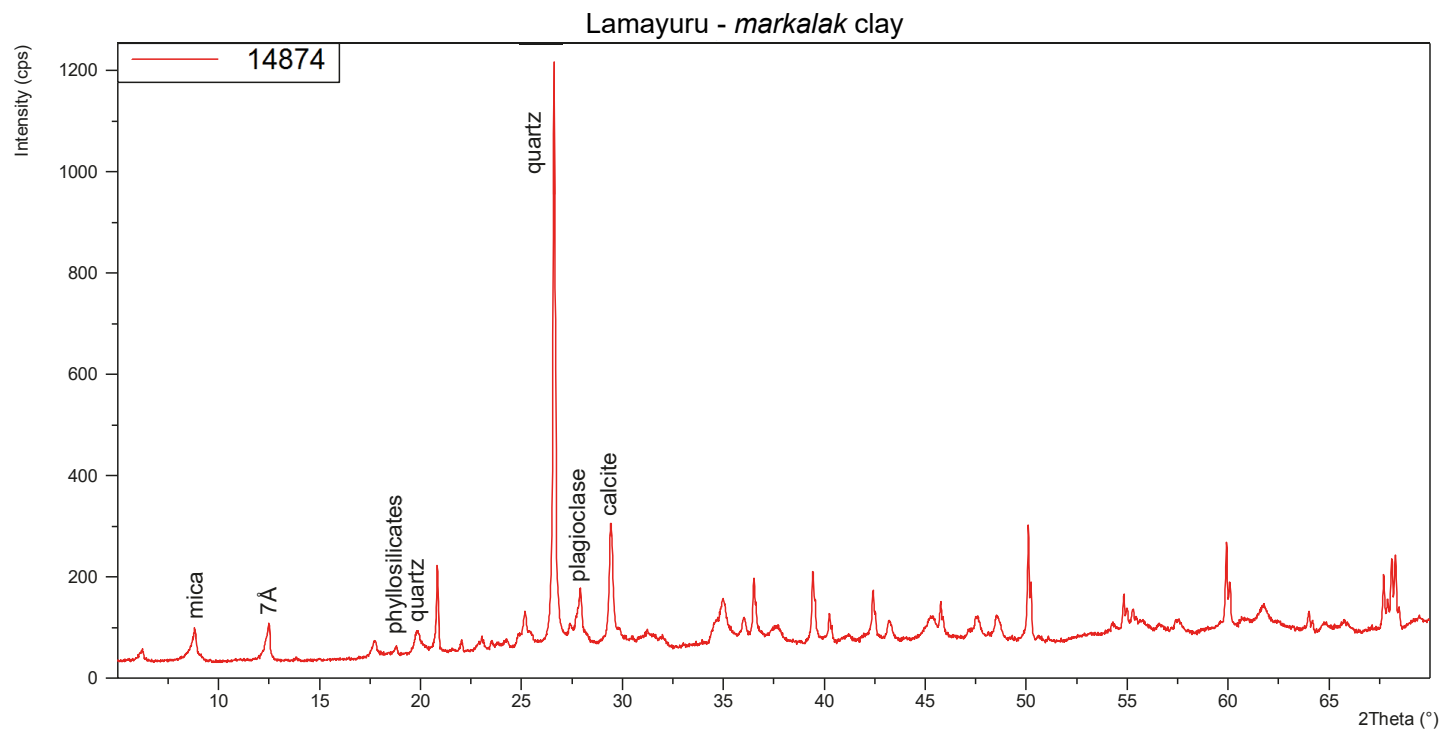

BMA 9.4 Lamayuru. Sample 14874. Markalak clay. Bulk mineral analysis.

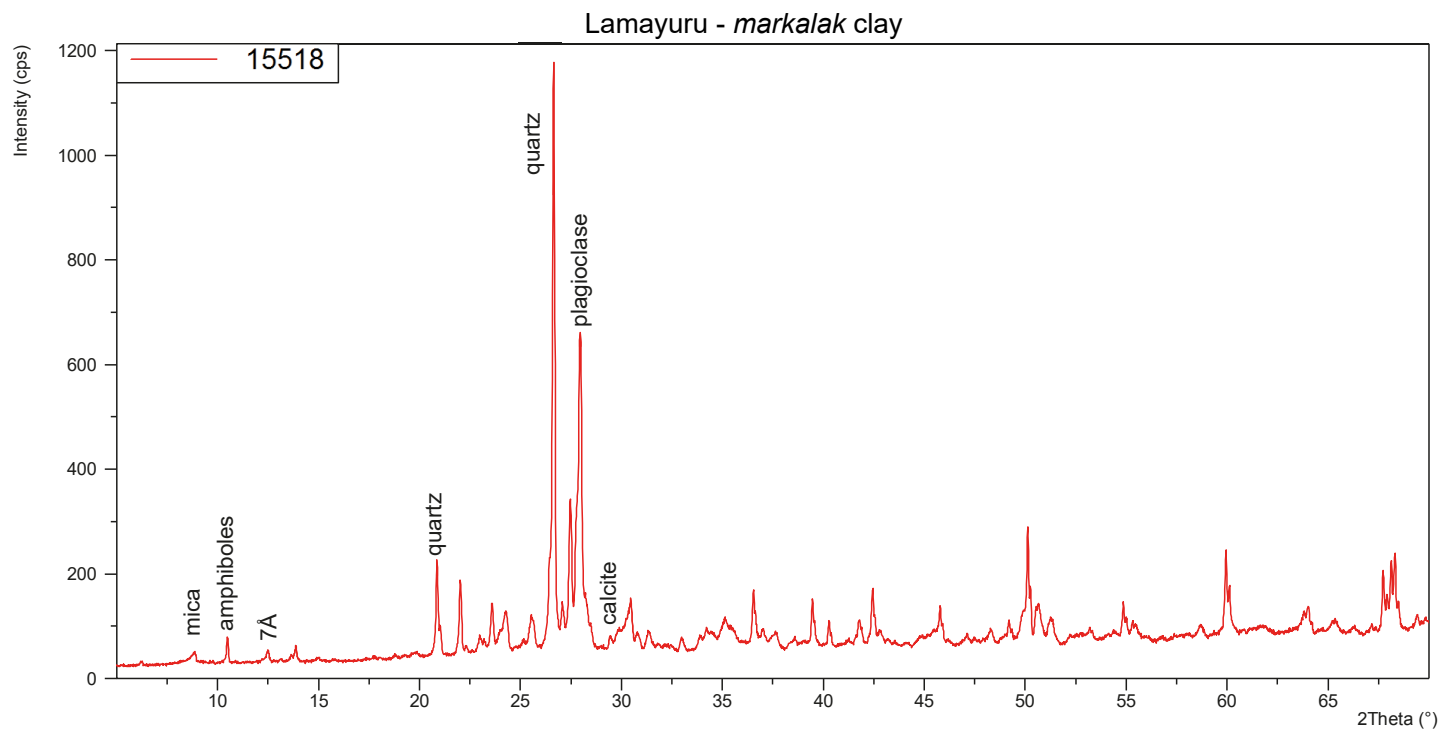

BMA 10.4 Basgo. Sample 15518. Markalak clay. Bulk mineral analysis. 


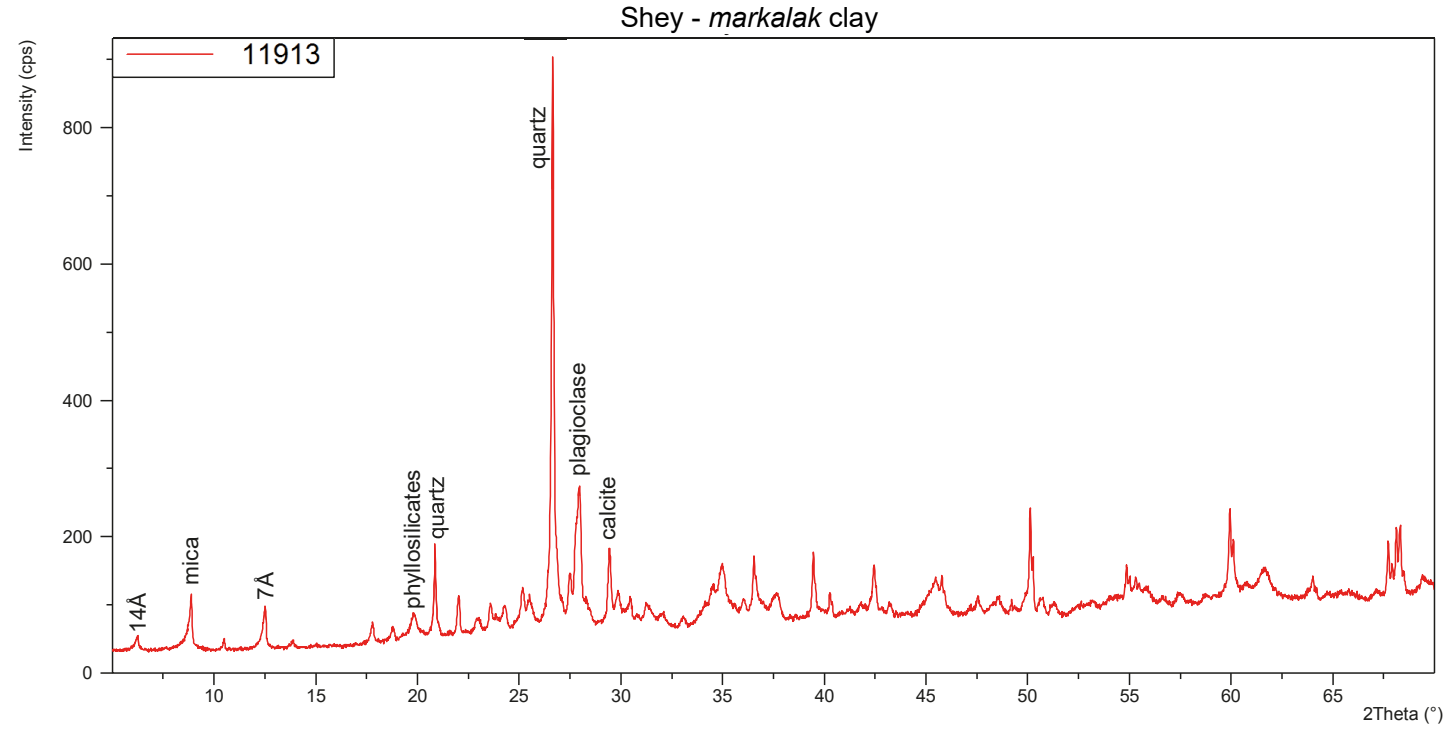

BMA 11.4 Shey. Sample 11913. Markalak clay. Bulk mineral analysis.

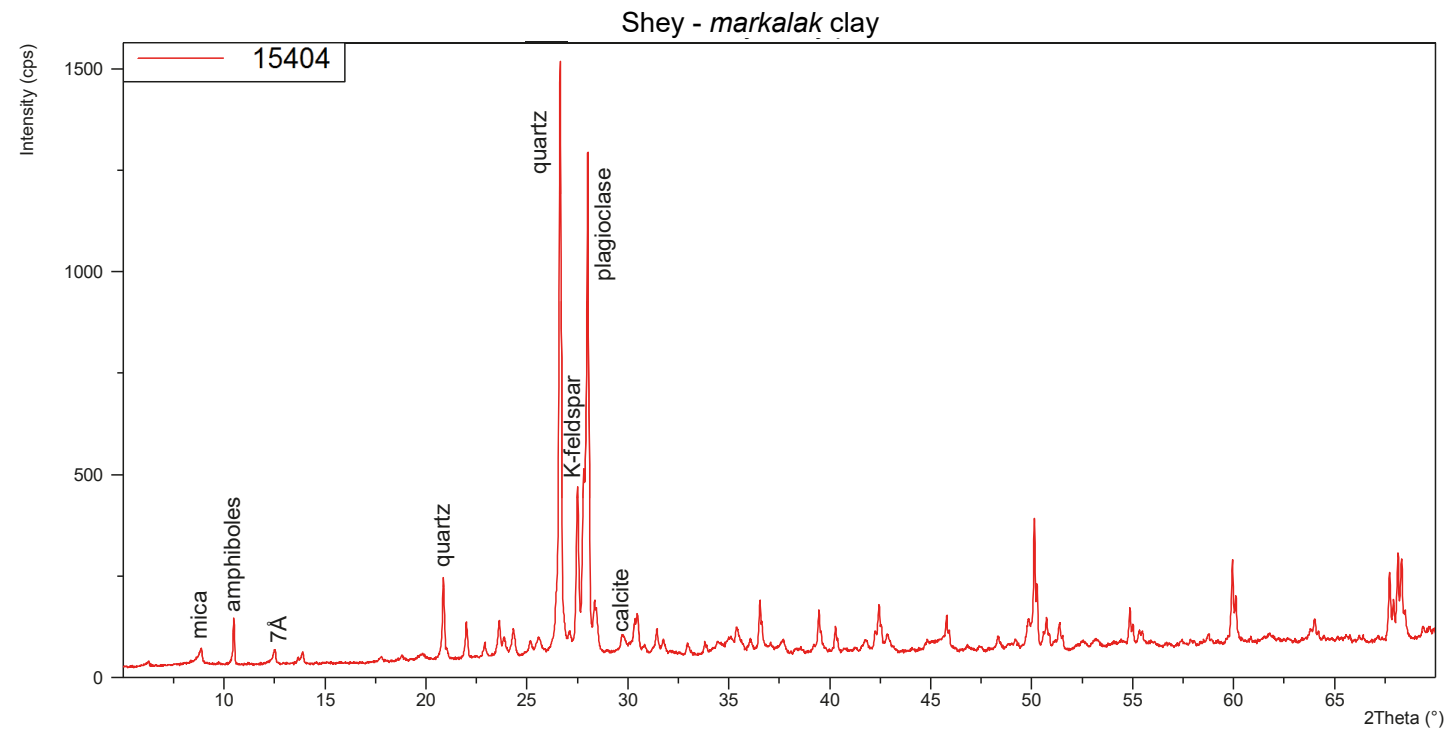

BMA 12.4 Lamayuru. Sample 15404. Clay pit for adobe bricks. Bulk mineral analysis. 


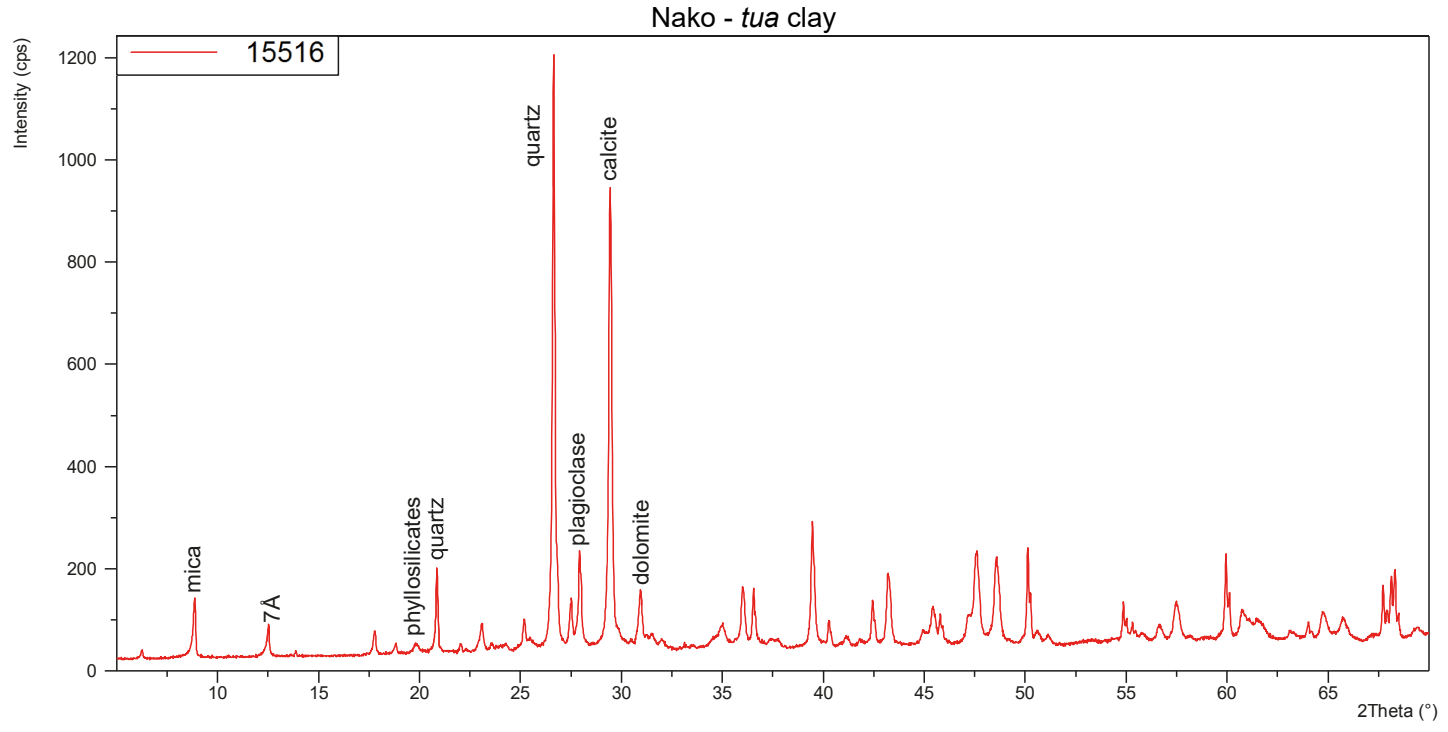

BMA 13.4 Nako. Sample 15516. Tua clay. Bulk mineral analysis.

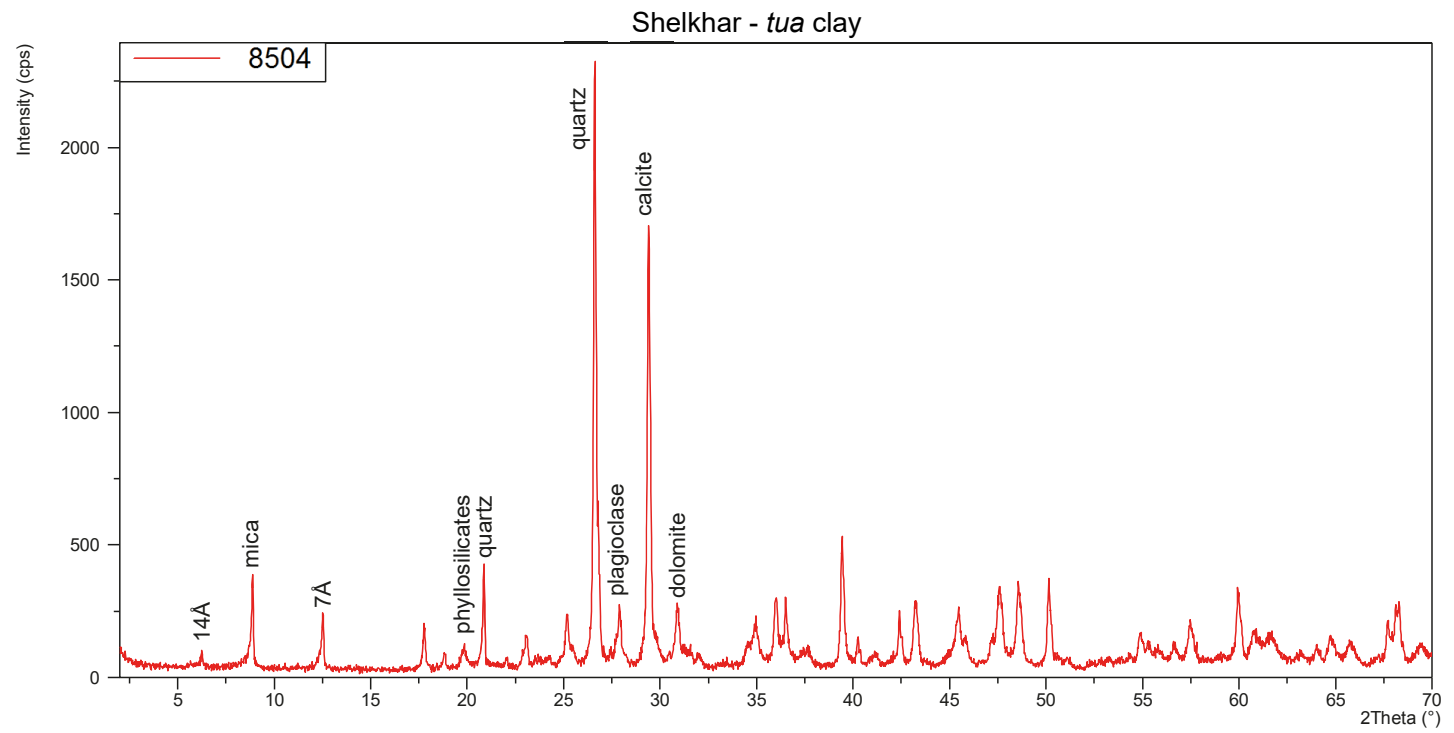

BMA 14.4 Shelkhar. Sample 8504. Tua clay. Bulk mineral analysis. 
Khorchag - narkalak clay

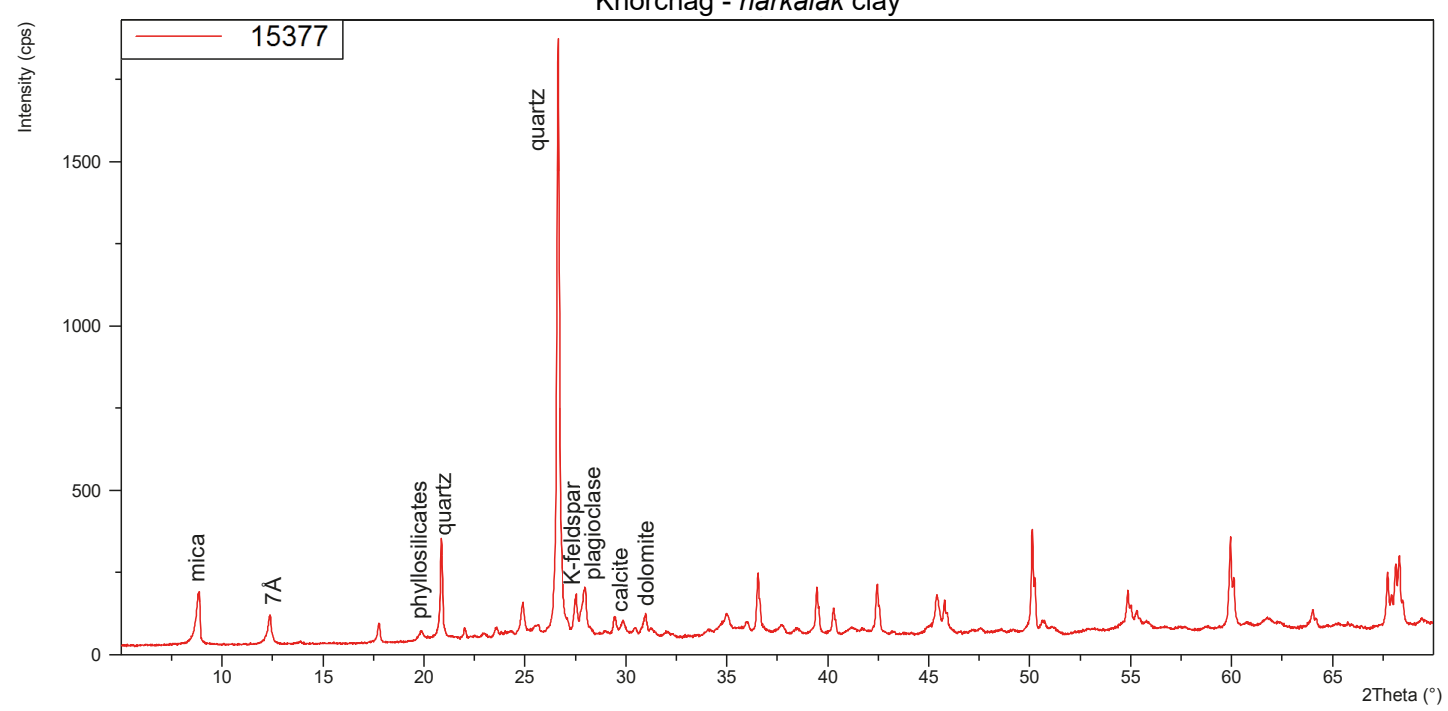

BMA 15.4 Khorchag. Sample 15377. Narkalak clay. Bulk mineral analysis.

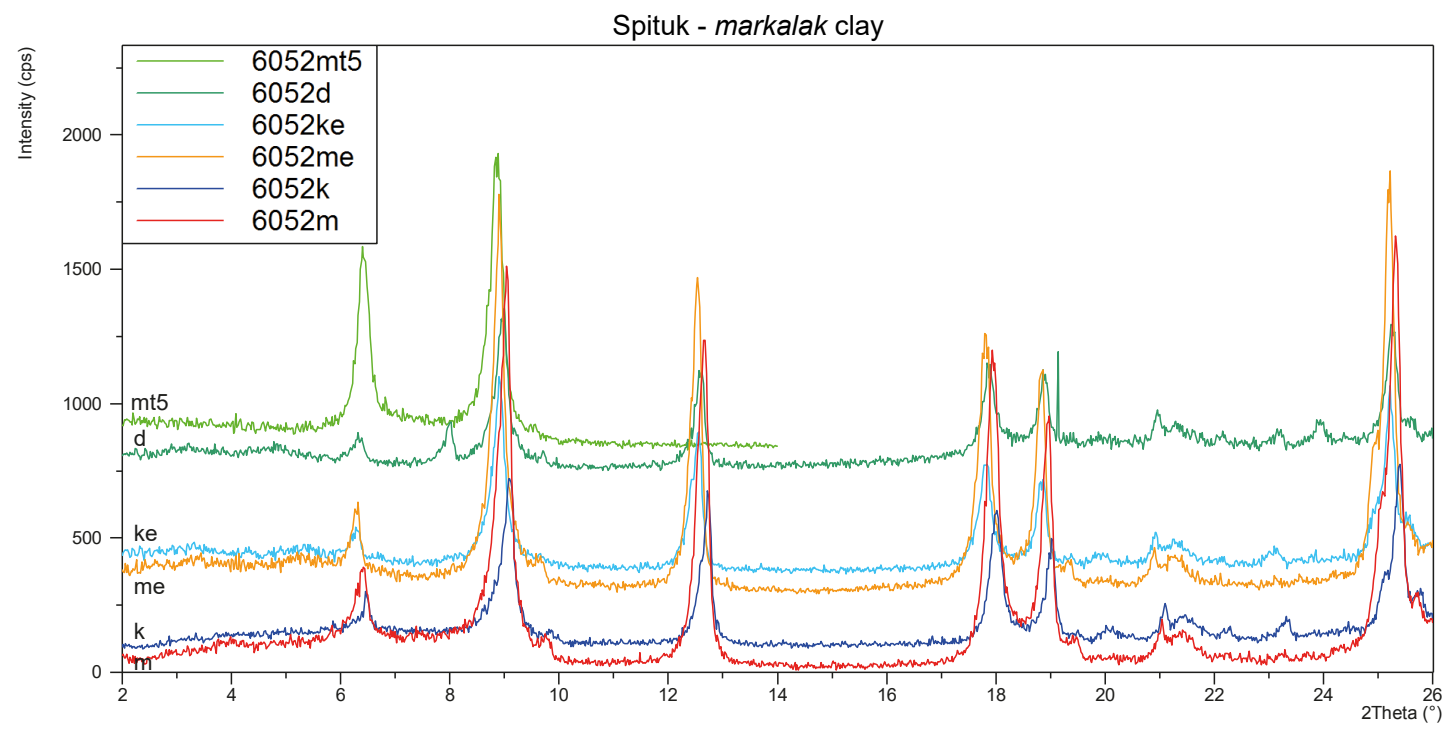

CMA 1.4 Spituk. Sample 6052. Markalak clay. Clay mineral analysis. 
Spituk - markalak clay

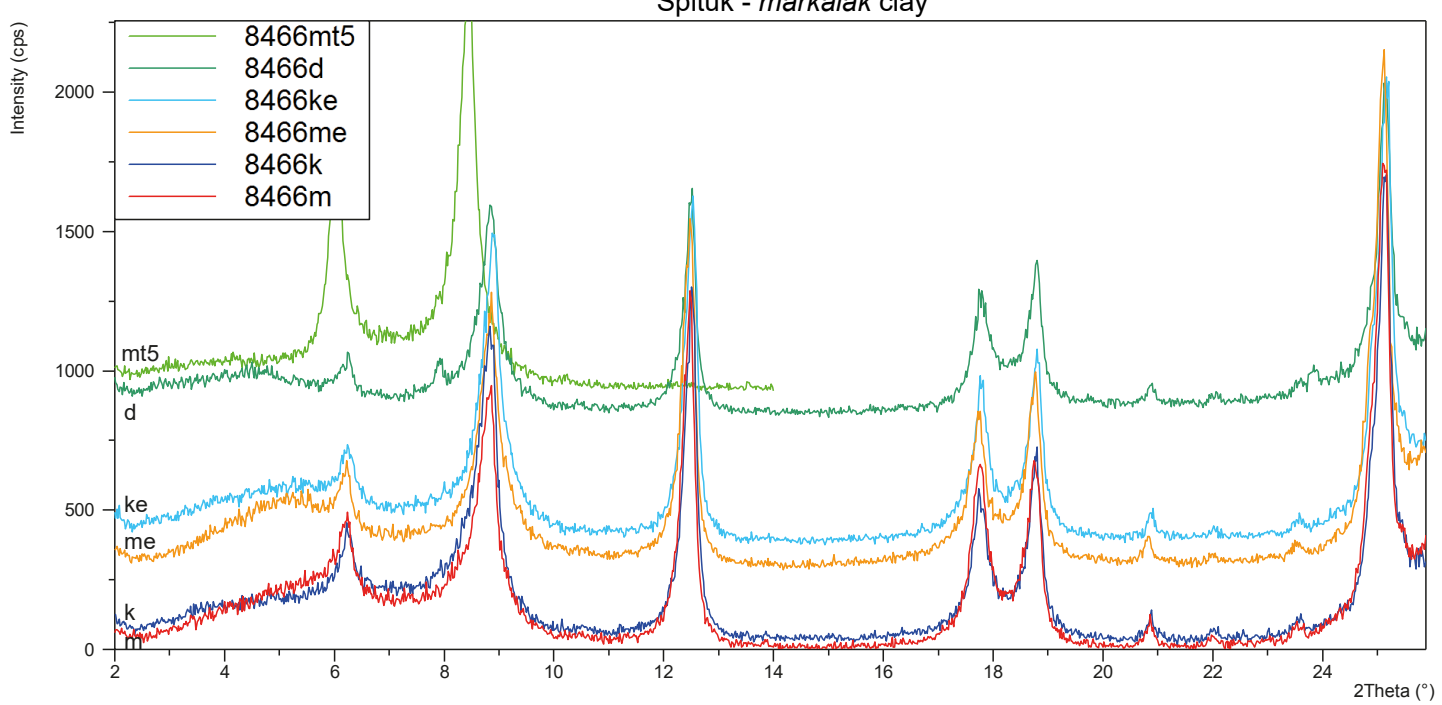

CMA 2.4 Spituk. Sample 8466. Markalak clay. Clay mineral analysis.

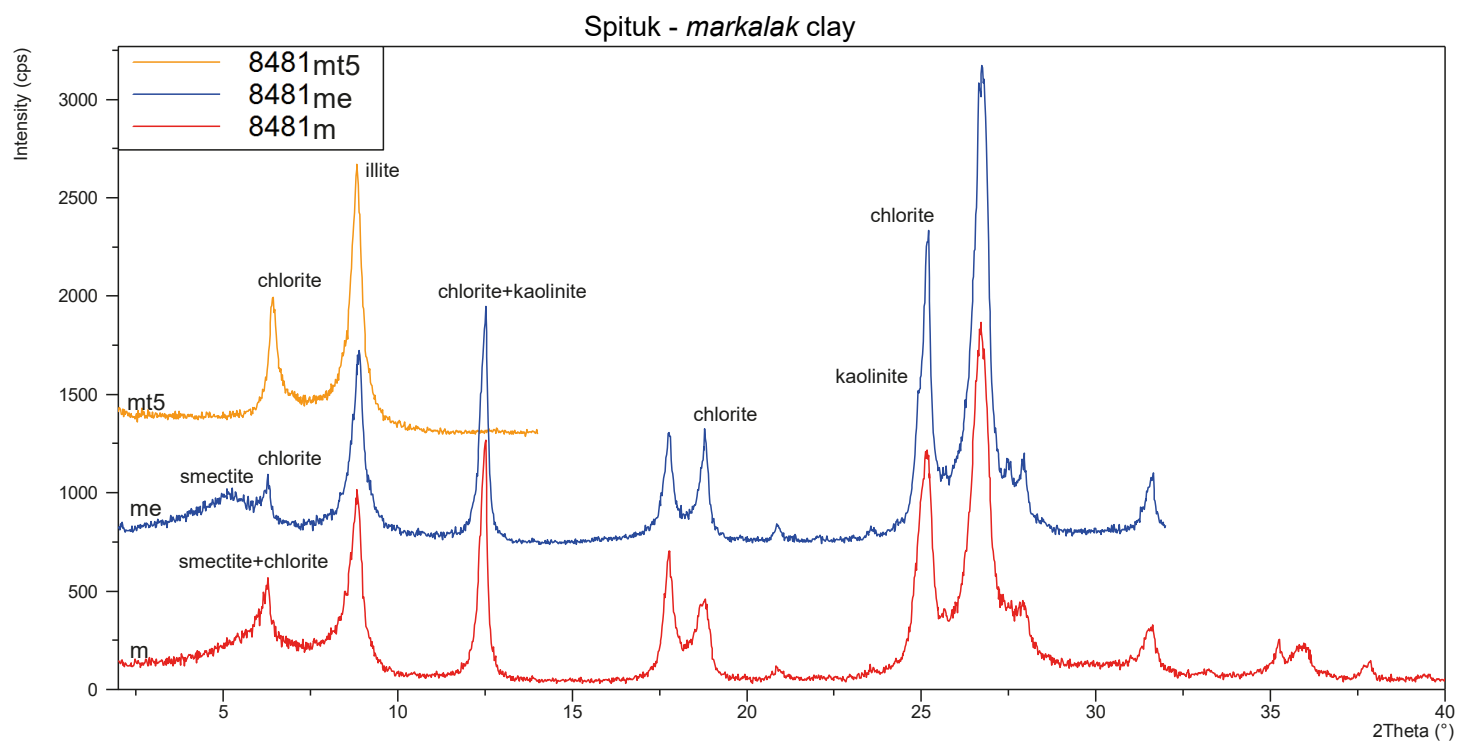

CMA 3.4 Spituk. Sample 8481. Markalak clay. Clay mineral analysis. 
Spituk - markalak clay

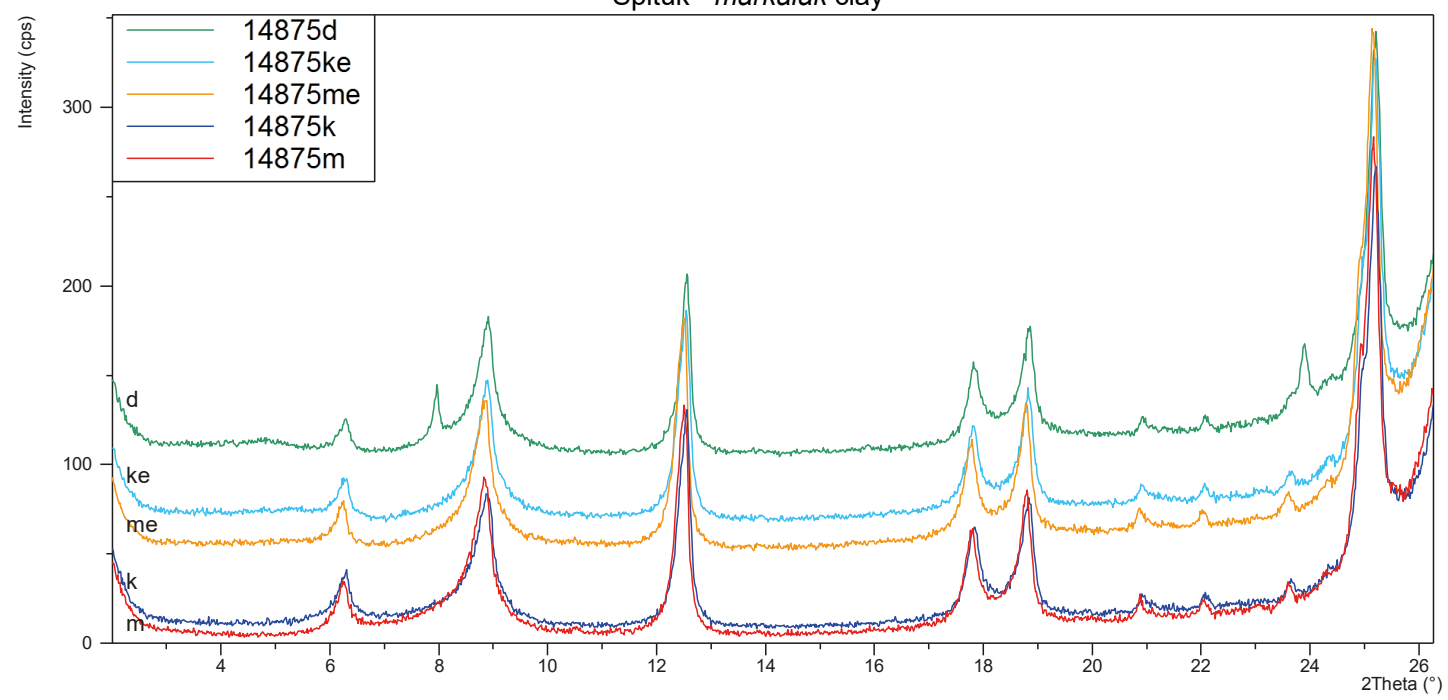

CMA 4.4 Spituk. Sample 14875. Markalak clay. Clay mineral analysis.

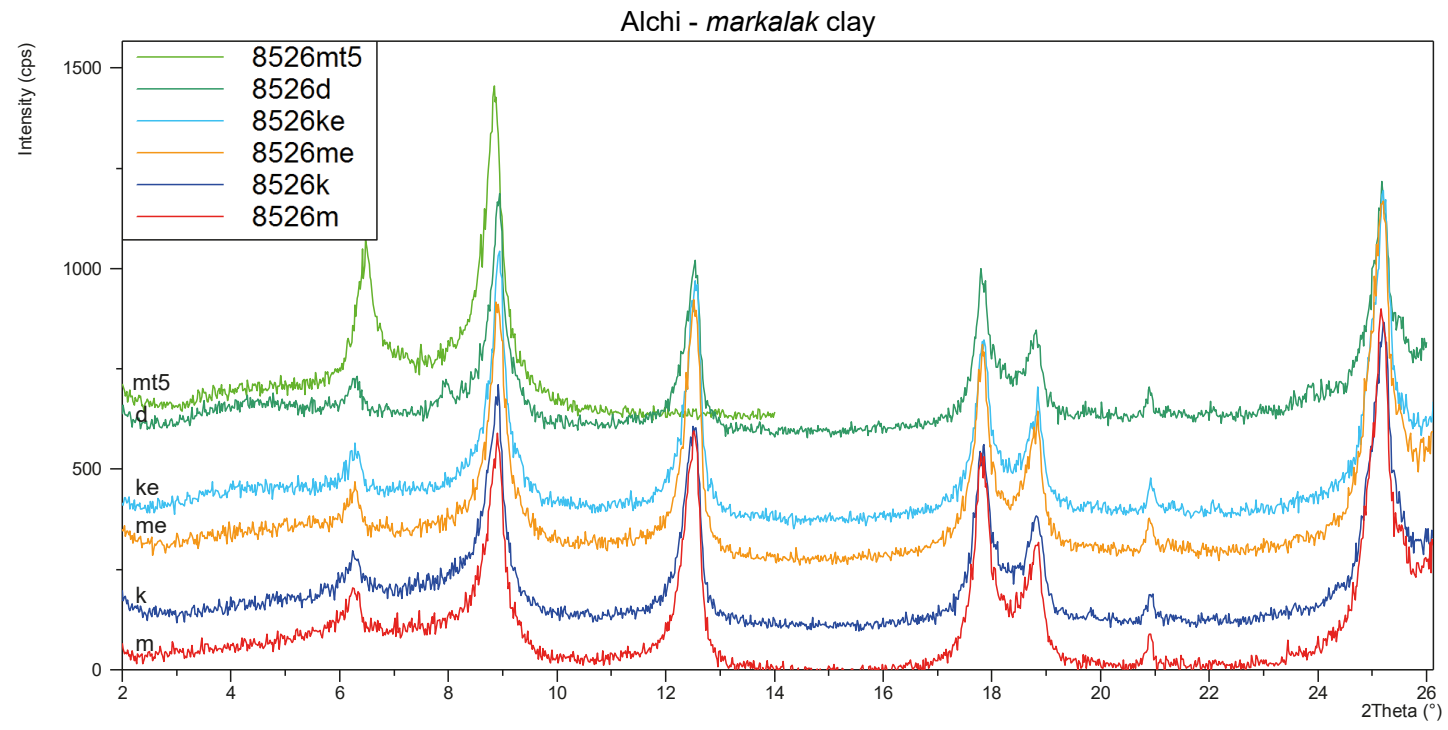

CMA 5.4 Spituk. Sample 8526. Markalak clay. Clay mineral analysis. 


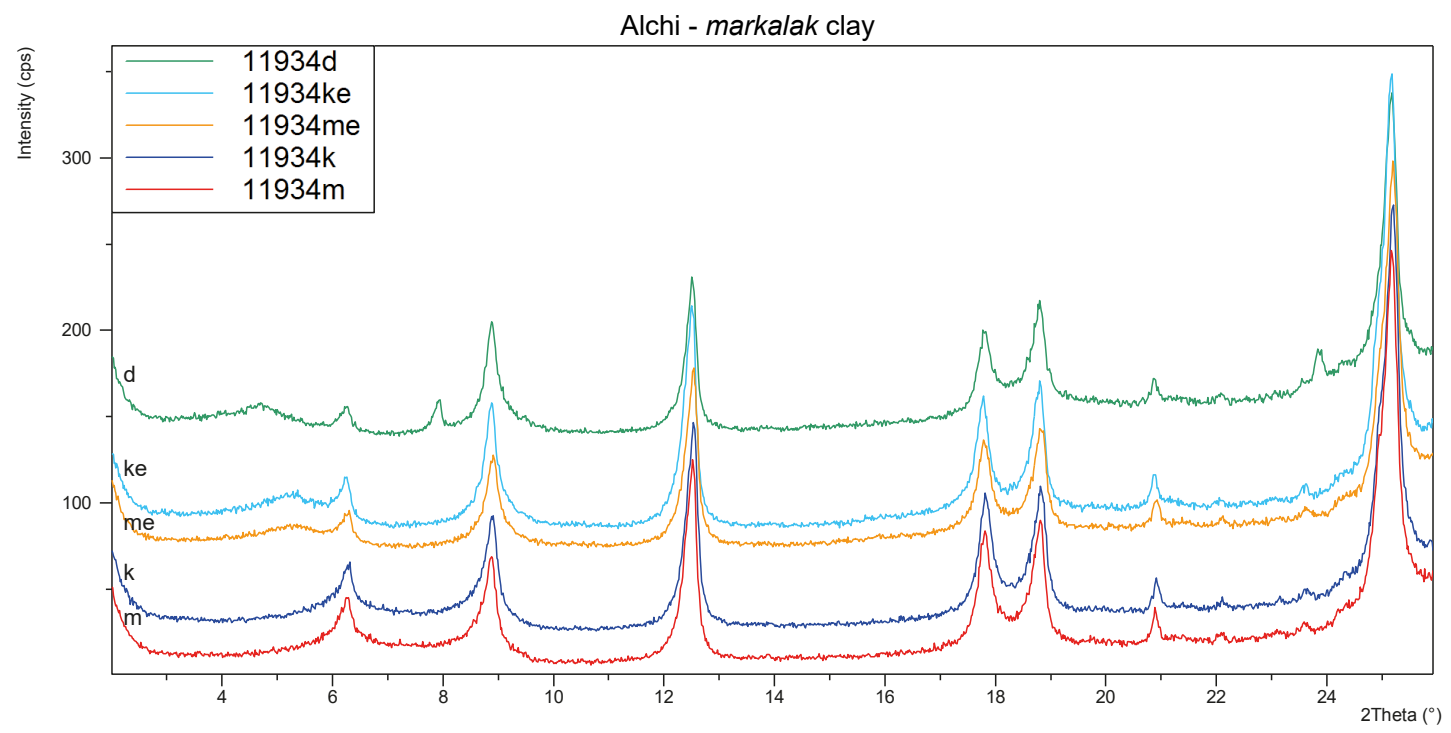

CMA 6.4 Alchi. Sample 11934. Markalak clay. Clay mineral analysis.

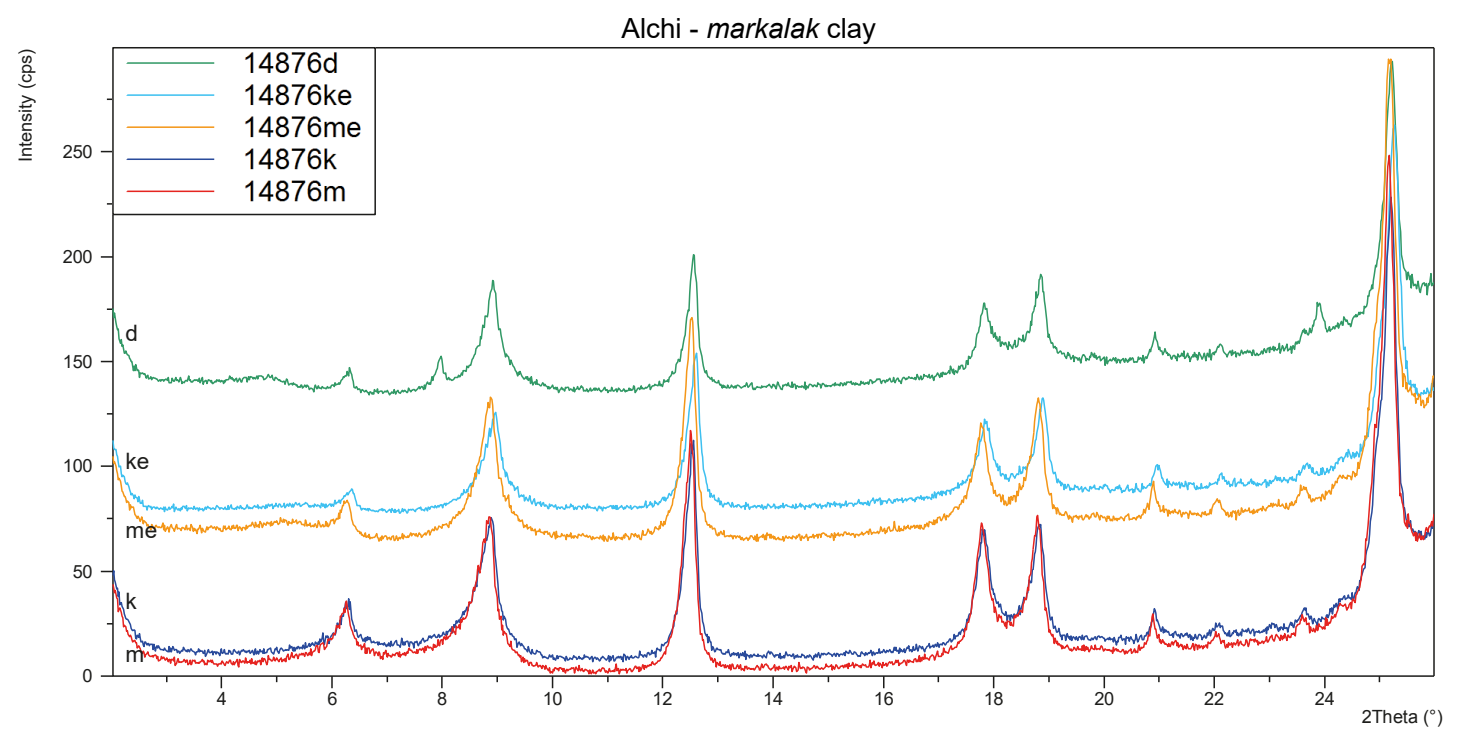

CMA 7.4 Alchi. Sample 14876. Markalak clay. Clay mineral analysis. 


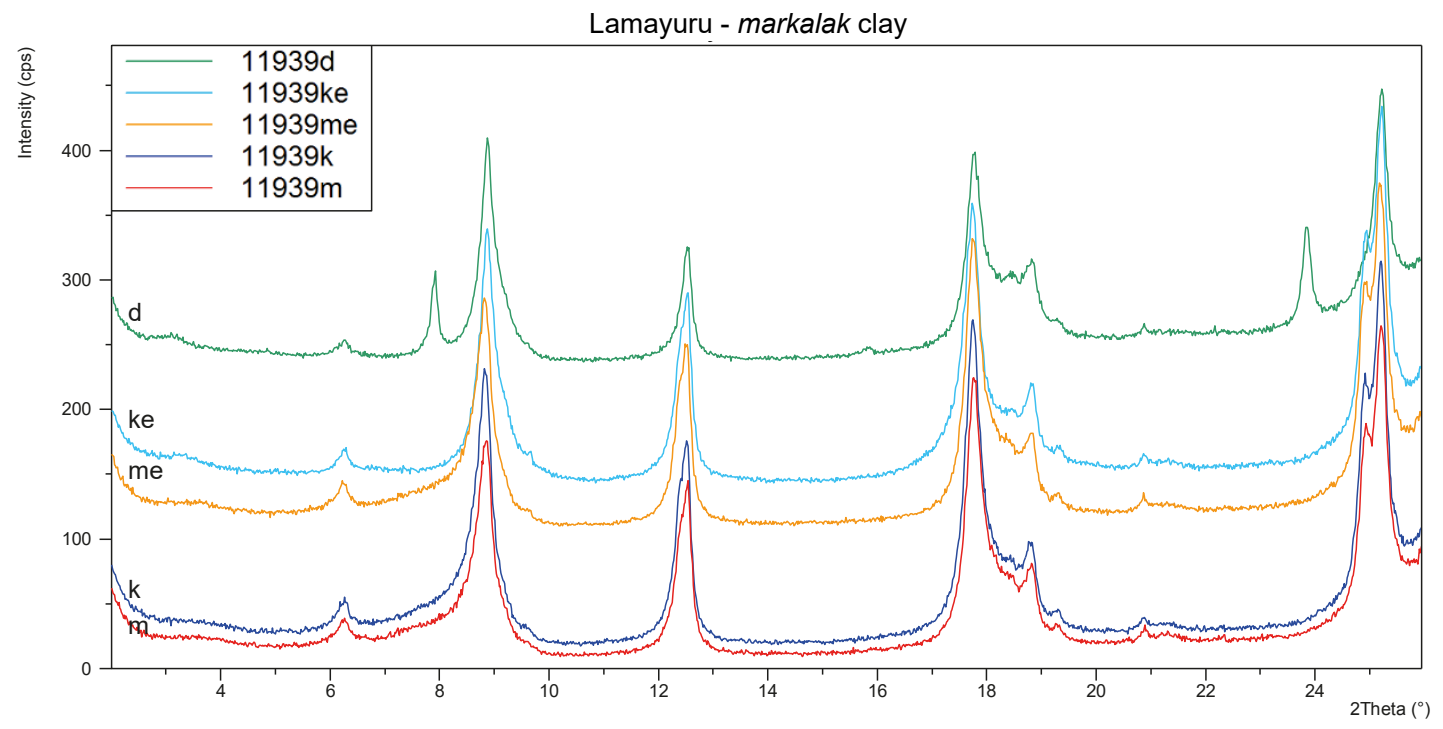

CMA 8.4 Lamayuru. Sample 11939. Markalak clay. Clay mineral analysis.

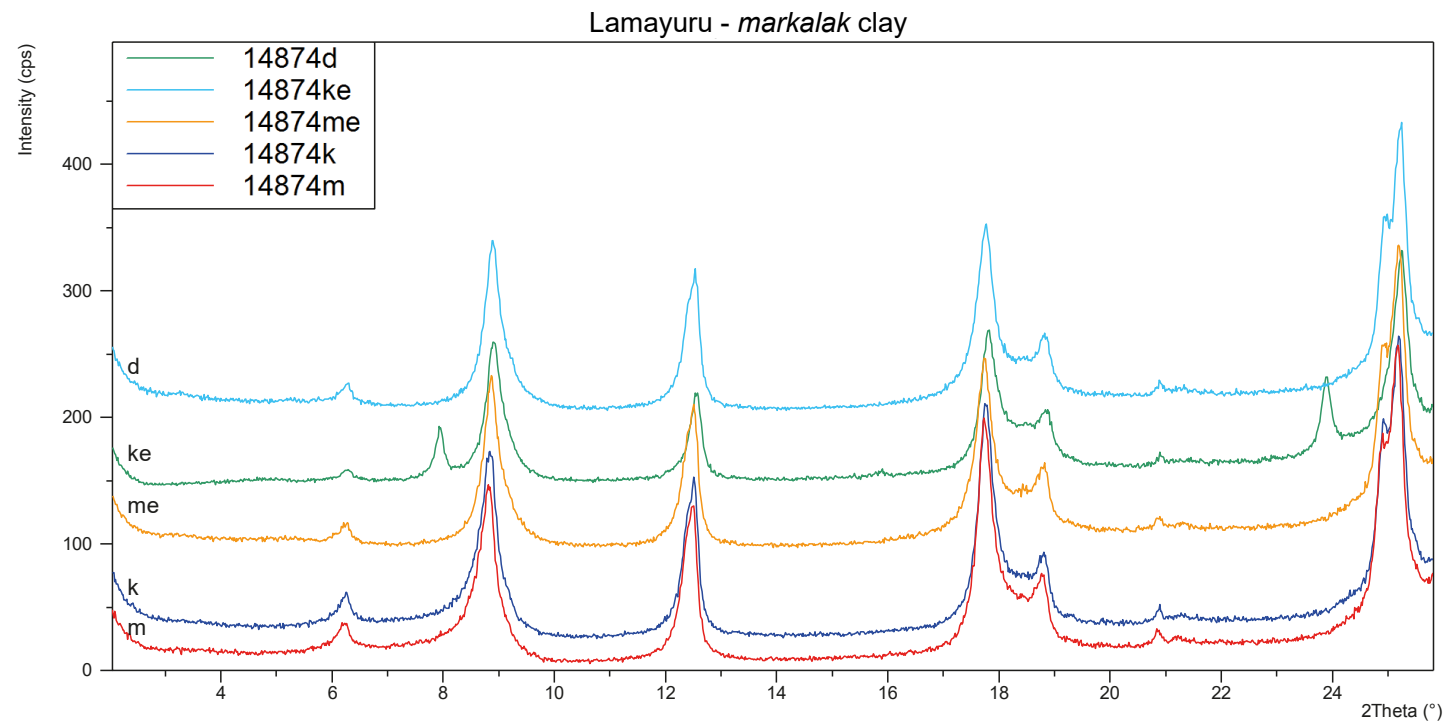

CMA 9.4 Lamayuru. Sample 14874. Markalak clay. Clay mineral analysis. 


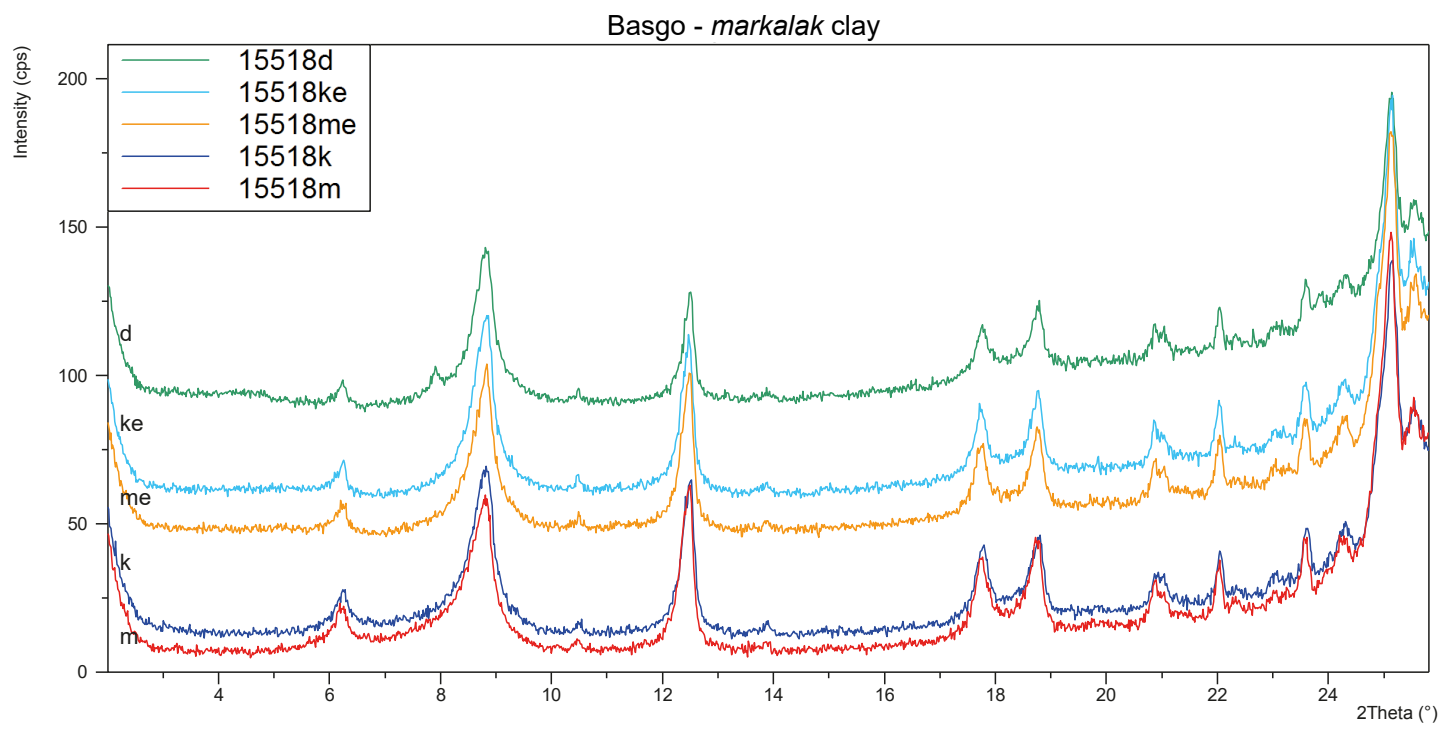

CMA 10.4 Basgo. Sample 15518. Markalak clay. Clay mineral analysis.

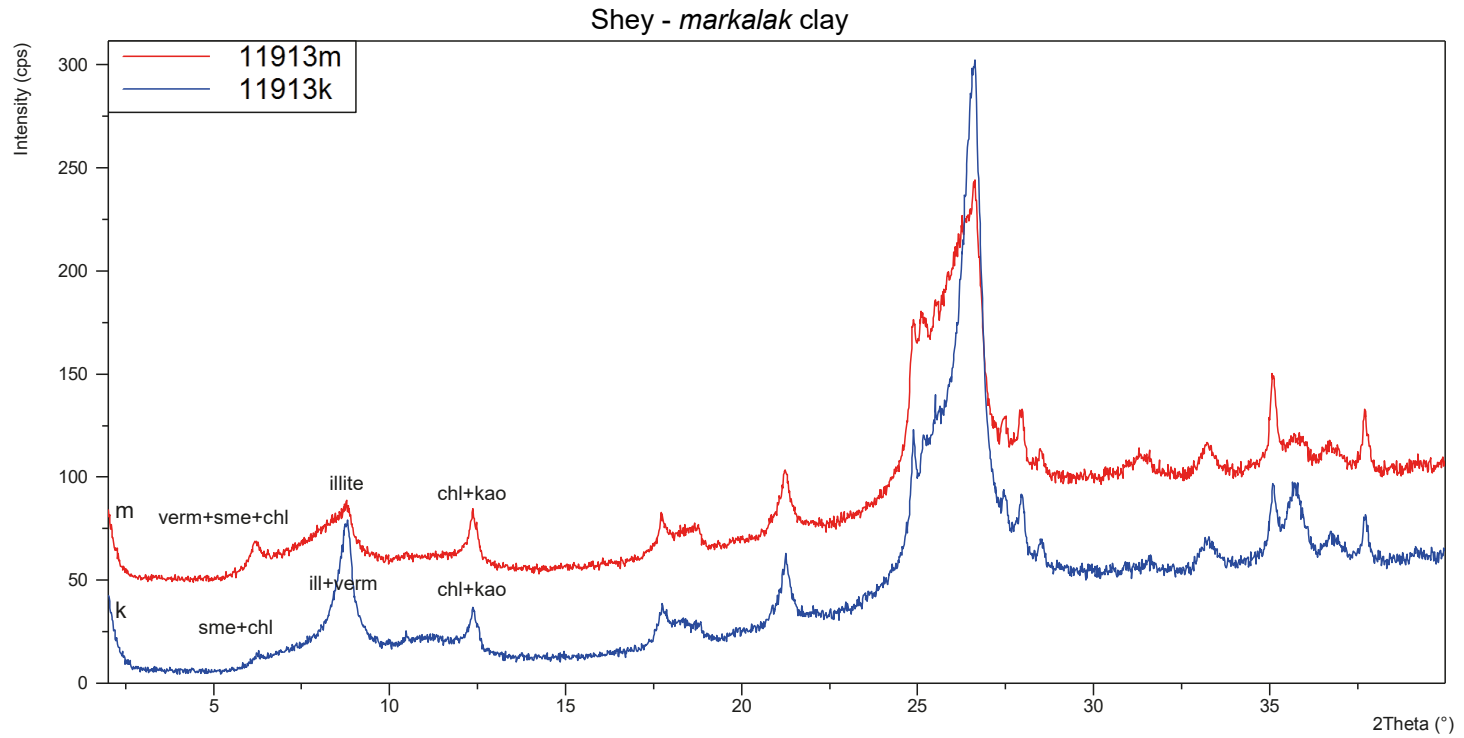

CMA 11.4 Shey. Sample 11913. Markalak clay. Clay mineral analysis. 


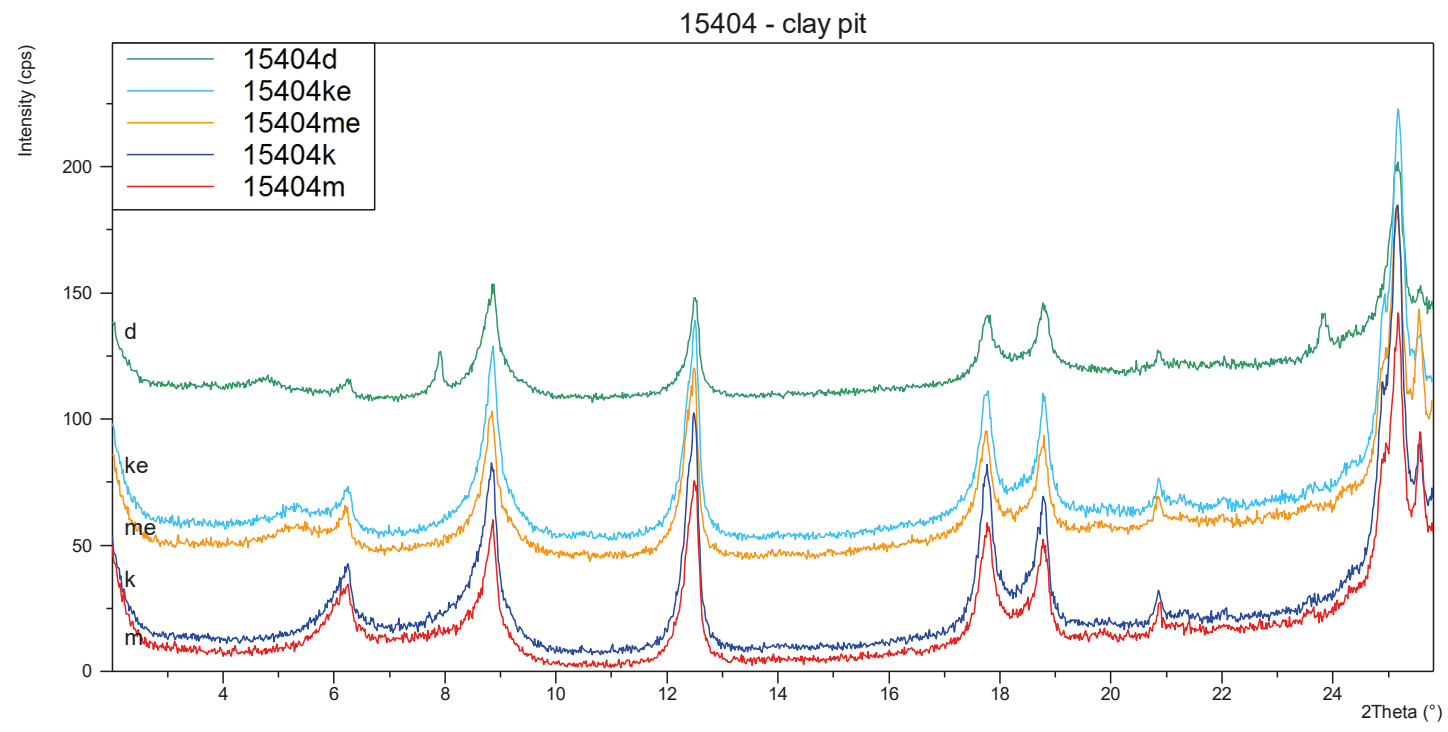

CMA 12.4 Shey. Sample 15404. Clay pit for adobe bricks. Clay mineral analysis.

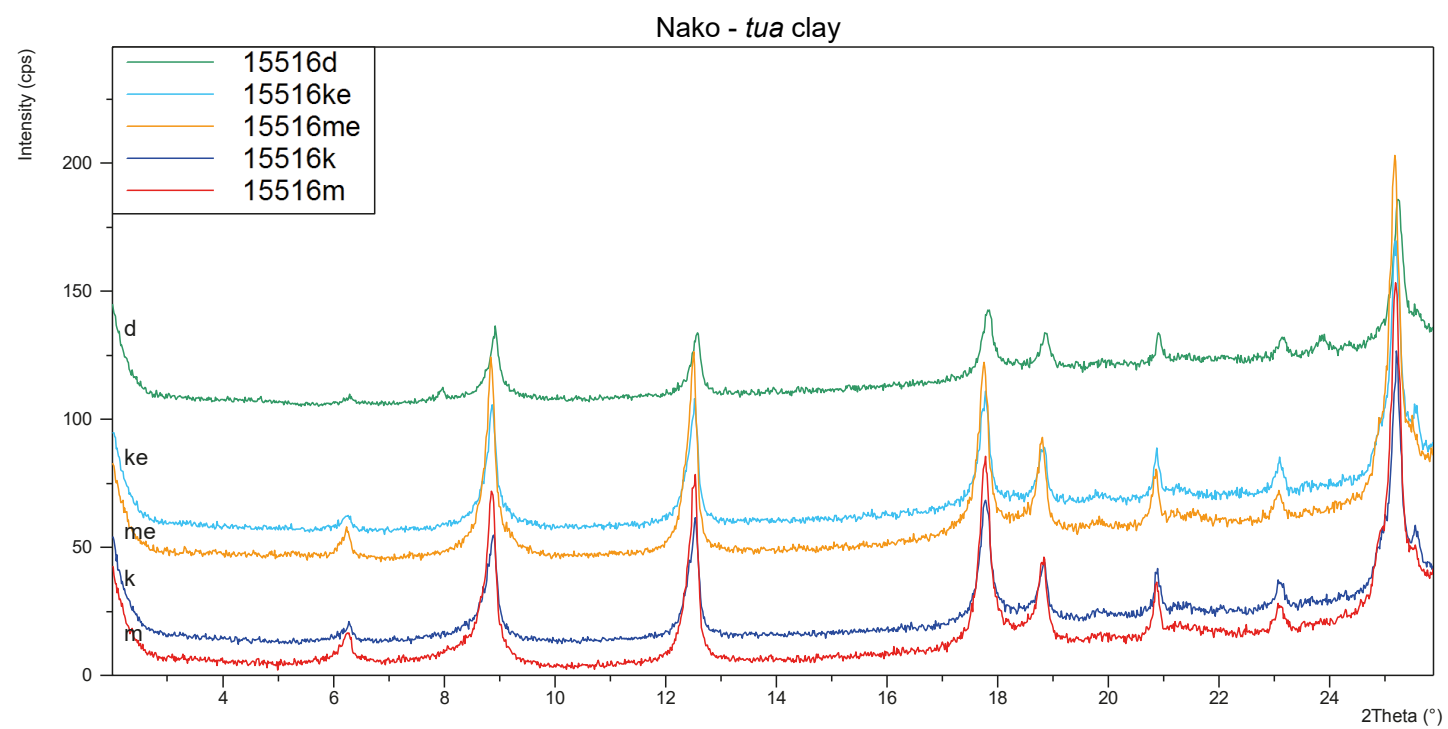

CMA 13.4 Nako. Sample 15516. Tua clay. Clay mineral analysis. 


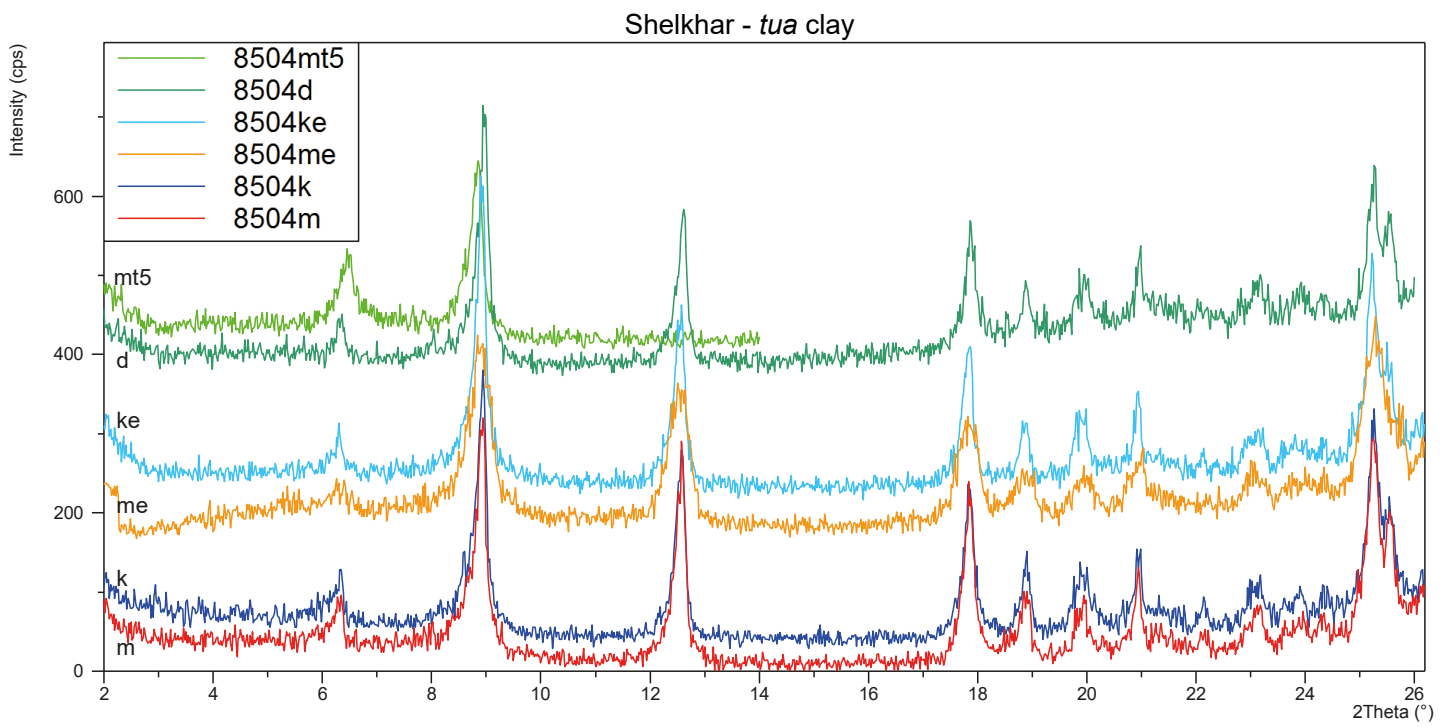

CMA 14.4 Shelkhar. Sample 8504. Tua clay. Clay mineral analysis.

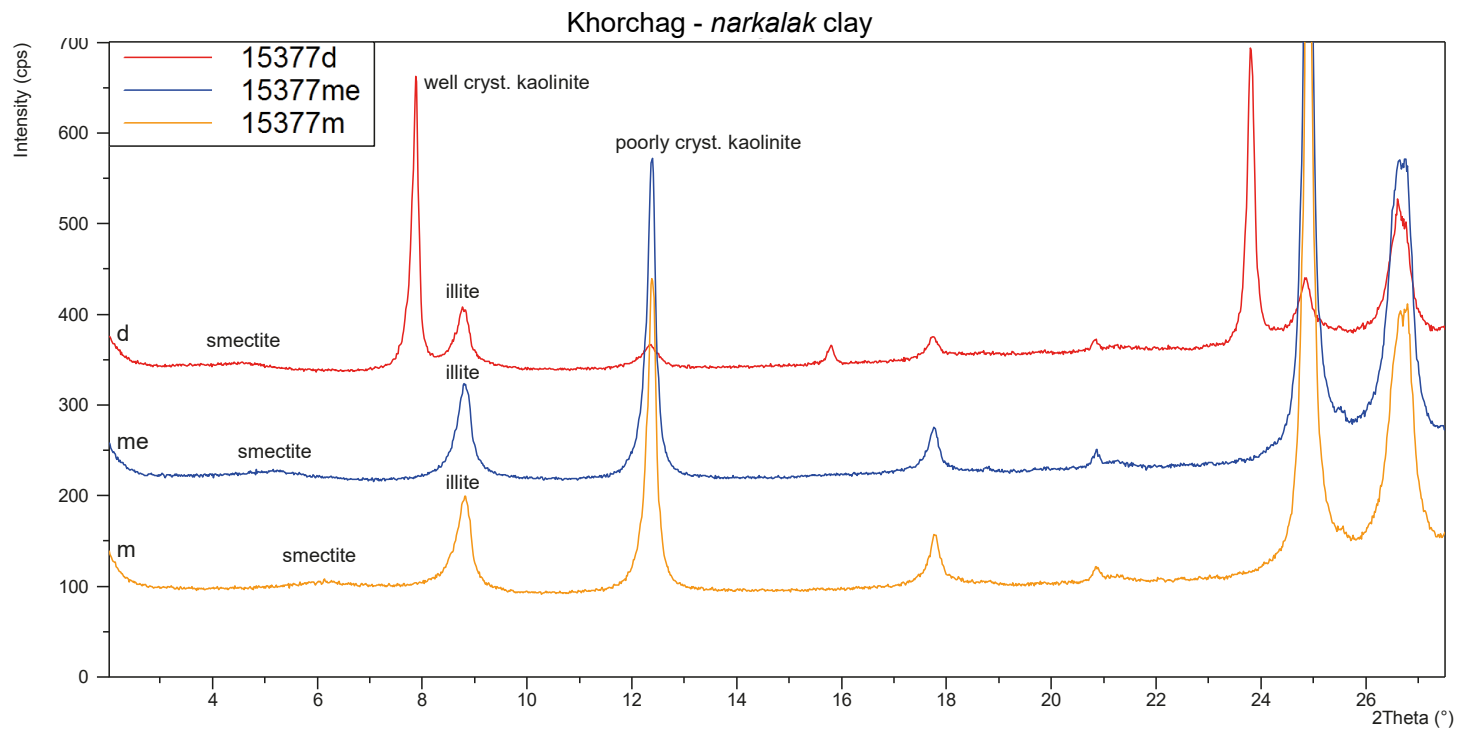

CMA 15.4 Khorchag. Sample 15377. Narkalak clay. Clay mineral analysis. 


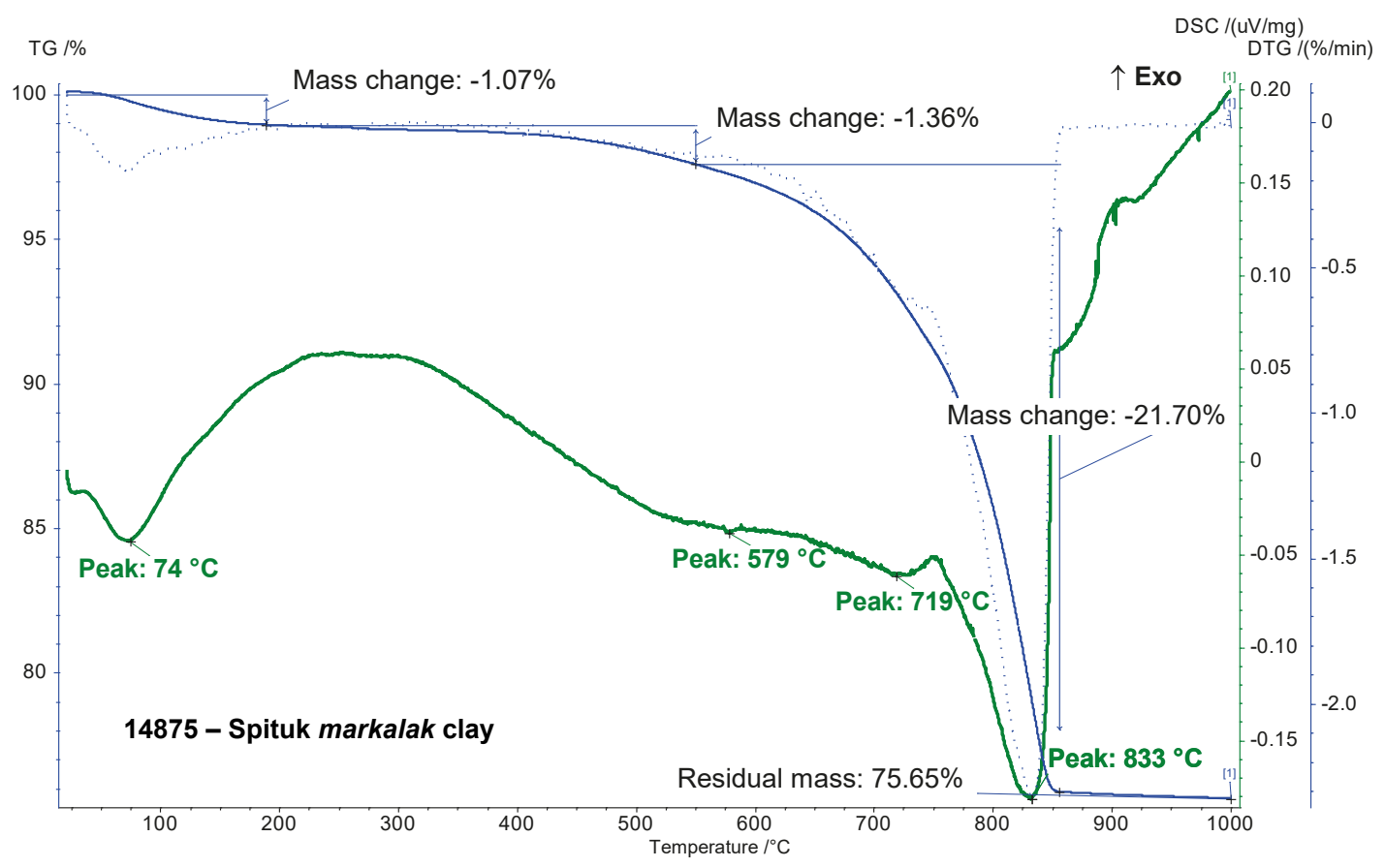

STA 1.4 Spituk. Sample 14875. Markalak clay. Simultaneous thermal analysis.

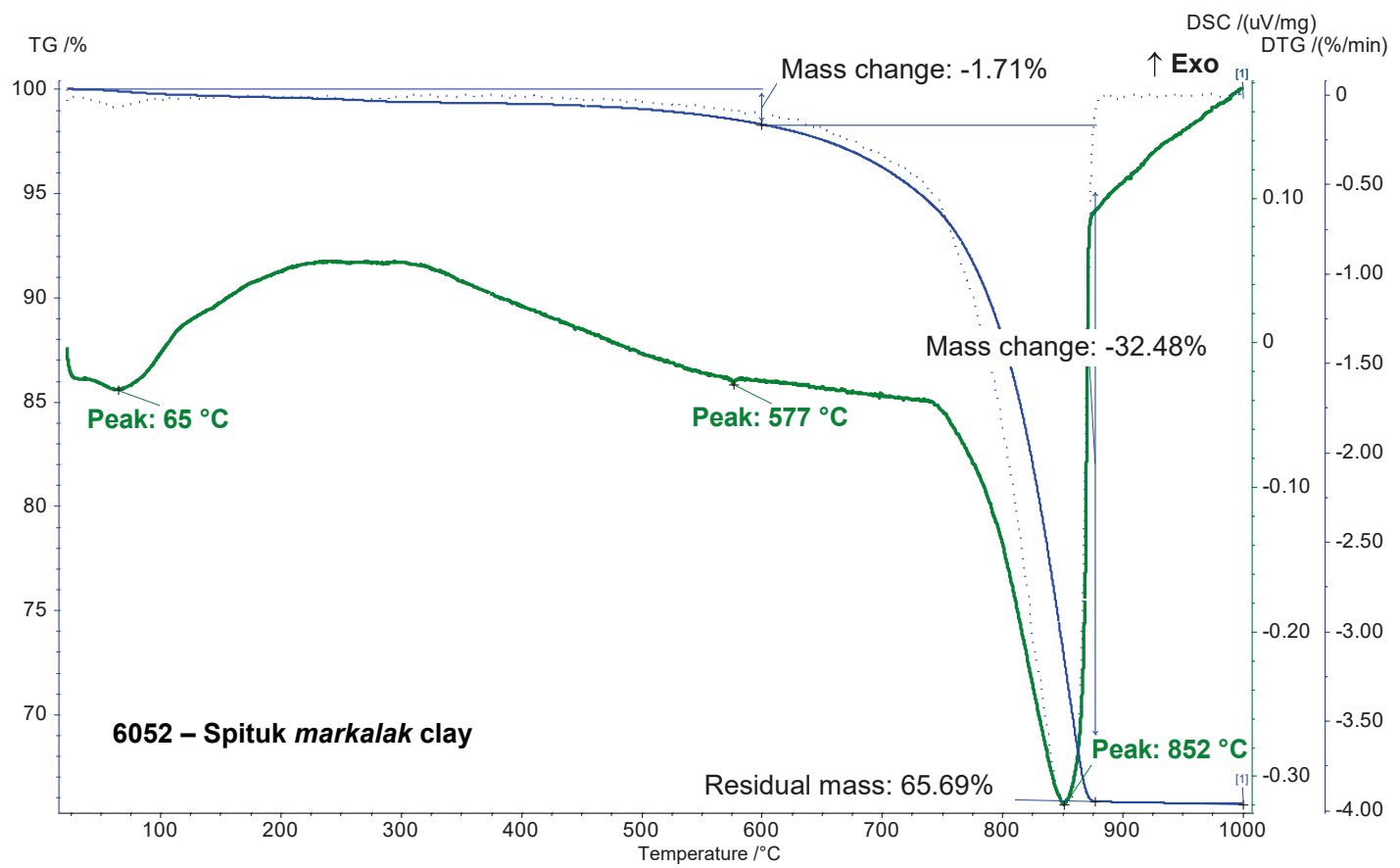

STA 2.4 Spituk. Sample 6052. Markalak clay. Simultaneous thermal analysis. 